\title{
Involvement of the GABAergic system in the neuroprotective and sedative effects of acacetin 7-O-glucoside in rodents
}

\author{
Javier Gálvez ${ }^{\mathrm{b}, 1}$, Rosa Estrada-Reyes ${ }^{\mathrm{a}, 1}$, Gloria Benítez-King ${ }^{\mathrm{d}, \mathrm{f}}$, Gabriela Araujo ${ }^{\mathrm{a}}$, Sandra Orozco ${ }^{\mathrm{g}}$, \\ Rodrigo Fernández-Mas ${ }^{\mathrm{c}}$, Salvador Almazán ${ }^{\mathrm{e}}$ and Eduardo Calixto ${ }^{\mathrm{b}, *}$ \\ ${ }^{a}$ Laboratory of Phytopharmacology, National Institute of Psichiatry, D.F., México \\ ${ }^{\mathrm{b}}$ Department of Neurobiology, National Institute of Psichiatry, D.F., México \\ ${ }^{\mathrm{c}}$ Laboratory of Neurophysiology of Control and Regulation, National Institute of Psichiatry, D.F., México \\ ${ }^{\mathrm{d}}$ Laboratory of Neuropharmacology, National Institute of Psichiatry, D.F., México \\ ${ }^{\mathrm{e}}$ Departament of Bioelectronics, National Institute of Psichiatry, D.F., México \\ ${ }^{\mathrm{f}}$ National Institute of Psichiatry, D.F, Ramón de la Fuente Muñí, Calzada México-Xochimilco 101, \\ Col. San Lorenzo Huipulco, Delegación Tlalpan, 14370 México, D.F., México \\ ${ }^{\mathrm{g}}$ Unit of Medical Research in Neurologic Deseases (UIMEN), Hospital de Especialidades, Medical National \\ Center Century XXI, Mexican Institute of Social Security, Av. Cuauhtémoc \#330, Col. Doctores, \\ Del. Cuauhtémoc, México, D.F., México
}

\begin{abstract}
.
Purpose: Characterization of sedative, possible anticonvulsant, and protective effects of Acacetin-7-O-glucoside (7-ACAG). Methods: 7-ACAG was separated and its purity was analyzed. Its sedative and anti-seizure effects $(1,10,20$, and $40 \mathrm{mg} / \mathrm{kg})$ were evaluated in male mice. Synaptic responses were acquired from area CA1 of hippocampal slices obtained from male Wistar rats. Rats were subjected to stereotaxic surgeries to allow Electroencephalographic (EEG) recordings. Functional recovery was evaluated by measuring the time rats spent in completing the motor task. Then the rats were subjected to right hemiplegia and administered 7-ACAG $(40 \mathrm{mg} / \mathrm{kg}) 1 \mathrm{~h}$ or $24 \mathrm{~h}$ after surgery. Brains of each group of rats were prepared for histological analysis. Results: Effective sedative doses of 7-ACAG comprised those between 20 and $40 \mathrm{mg} / \mathrm{kg}$. Latency and duration of the epileptiform crisis were delayed by this flavonoid. 7-ACAG decreased the synaptic response in vitro, similar to Gamma-aminobutyric acid (GABA) effects. The flavonoid facilitated functional recovery. This data was associated with preserved cytoarchitecture in brain cortex and hippocampus.

Conclusions: 7-ACAG possesses anticonvulsive and sedative effects. Results suggest that GABAergic activity and neuroprotection are involved in the mechanism of action of 7-ACAG and support this compound's being a potential drug for treatment of anxiety or post-operative conditions caused by neurosurgeries.
\end{abstract}

Keywords: Flavonoids, $\mathrm{GABA}_{\mathrm{A}}$, hemiplegia, functional recovery

\footnotetext{
${ }^{1}$ Gálvez J and Estrada-Reyes R: Contributed equally to this work.

*Corresponding author: Eduardo Calixto, Departamento de Neurobiología, Dirección de Investigaciones en Neurociencias, Instituto Nacional de Psiquiatría Ramón de la Fuente Muñiz, Calzada MéxicoXochimilco 101, Col. San Lorenzo Huipulco, Del. Tlalpan, 14370 México, D.F., México. Tel.: +52 541 605089; Fax: +52 5655 9980; E-mail: ecalixto@imp.edu.mx.
}

\section{Introduction}

Acacetin-7-O-glucoside (7-ACAG) is a flavone glycoside (7- $\beta$-D-glucopyranosyloxy)-5-hydroxy2-(4-methoxyphenyl)-4H-1-benzopyran-4-one, syn; 
tilianin). It is isolated from Agastache mexicana subsp. mexicana (Amm) and Agastache mexicana subsp. xolocotziana (Amx), which are known as "toronjil morado" and "toronjil blanco" (purple and white hyssops; Estrada-Reyes, 2004). Both species are employed not only as tranquilizers and sleep inducers, but also as treatment for anxiety. They are usually utilized alone or prepared in combination with the following: "toronjil azul" or "toronjil extranjero", that is, blue hyssop or foreign hyssop, and Dracocephalum moldavica L. (Bye \& Linares, 1983; Bye et al., 1987).

Our group previously described the Central nervous system (CNS) depressant properties of an aqueous extract of Dracocephalum moldavica (Dm). Recently, we described the anxiolytic-like and sedative effects of aqueous extracts of Amm and Amx. The chemical characterization of all of these three aqueous extracts showed that these complex mixtures abound in flavonoid compounds. Among these, 7-ACAG, together with its malic ester derivate, are the main secondary metabolites present at a major proportion (Martínez-Vázquez et al., 2012; Estrada-Reyes et al., 2014). 7-ACAG possesses antihypertensive effects and mediates relaxation in an endothelium-dependent manner and also through an endothelium-independent pathway by opening $\mathrm{K}^{+}$channels (Hernández-Abreu et al., 2009). In addition, 7-ACAG ameliorates atherosclerosis by inhibiting the production of the Necrosis factor-beta (NF- $\beta$ )-dependent proinflammatory cytokines, Tumor nuclear factor (TNF), and Interleukin 1 (IL-1) via inhibition of IB kinase activity (Nam et al., 2005). However, to our knowledge, no behavioral studies and CNS effects of 7-ACAG in vivo have been reported to date.

In this regard, it is known that hesperidin, a flavanone glycoside isolated from citrus species, has anxiolyticlike, sedative, and possible anticonvulsant effects, as well as memory improvement and neuroprotection in rodents, while the flavanone rutinoside, neoponcirin, produces anxiolytic antinociceptive effects in mice (Fernández et al., 2006; Spencer et al., 2009; Zhang et al., 2013; Rueda et al., 2014; Meng et al., 2014; Cassani et al., 2013).

Antioxidant properties have been demonstrated in a broad spectrum of flavonoids. Therefore, they are good candidates for the treatment of neurodegenerative diseases. In particular, baicalein (Chinese skullcap) reduces $\beta$-amyloid plaques, an important protein involved in the pathophysiology of
Alzheimer disease (AZ) and possessing a potent scavenger effect (Wang et al., 2005; Yang et al., 2011).

Additionally, it has been proposed that some flavonoid compounds exert their CNS-depressant effects through their direct or indirect interaction with the Gamma-aminobutyric acid type $\mathrm{A}\left(\mathrm{GABA}_{\mathrm{A}}\right)$ neurotransmitter system. $\mathrm{GABA}_{\mathrm{A}}$ receptors are chloride channels that mediate the major form of fast inhibitory neurotransmission in the CNS. These receptors are activated by GABA and by their selective agonist, muscimol. Also, they are blocked by Bicuculline (BIC) and modulated by benzodiazepines, barbiturates, and certain other CNS depressants. Recently, it was identified that GABA is involved in the mechanisms of functional recovery of seizures caused by ischemic strokes (Kim et al., 2014). Although it is known that flavonoids exert their functional recovery effects through scavenger effects, the relationship between flavonoids and the $\mathrm{GABA}_{\mathrm{A}}$ receptor in functional recovery has, to our knowledge, not been studied.

Ischemic stroke has been established as an experimental model to understand the pathophysiology of brain damage and to study novel, useful biomolecules in the treatment of cerebral ischemic stroke. In recent years, new therapies based on the free radical scavenger properties of drugs have attracted close attention for the treatment of cerebral Hemiplegia $(\mathrm{Hp})$ and neuronal damage (Liu et al., 2013). Thus, antioxidant flavonoids, free and glycosylated, have been considered novel therapeutic alternatives for traumatic brain damage or for ischemic stroke (Yu et al., 2013; Wang et al., 2011).

The aims of the present study were the evaluation of the sedative and possible anticonvulsant effects of 7-ACAG in mouse behavioral models, its electrophysiological effects, and its ability to ameliorate $\mathrm{Hp}$-induced neuronal damage in rat. To accomplish these aims, the following experiments were conducted:

1) Sedative effects of 7-ACAG were evaluated in Hole-board (HBT) and Open field (OFT) behavioral tests in mice in comparison with those produced by a positive standard, Diazepam (DZ), a BDZ GABA agonist with anxiolytic sedative and antiepileptic effects.

2) The possible anticonvulsant effect of the 7ACAG was evaluated in BBIC-induced seizures 
in mice in comparison with those produced by $\mathrm{DZ}$.

3) The GABAergic changes induced by 7-ACAG in the CA1 hippocampal area were evaluated electrophysiologically in brain slices by comparing these with evoked GABA field Excitatory Postsynaptic Potentials (fEPSP).

4) The possible protective effects of 7-ACAG in rats with $\mathrm{Hp}$ produced by aspiration of the right somatomotor cortex were evaluated using the following three different and complementary techniques: A) functional recovery was measured behaviorally by using the Beam walking test (BWT); B) functional recovery was quantified electrophysiologically by recording the potency changes of the Electroencephalogram (EEG), and C) and histologically by analyzing the hippocampal tissue of hemiplegic rats treated with the vehicle, 7-ACAG, and the antioxidant $\alpha$ Tocopherol.

\section{Materials and methods}

\subsection{Drugs}

All drugs used in brain slices recordings were purchased from Sigma Chemical Company (St. Louis, MO, USA). Diazepam (DZ) was purchased from Hoffmann-La Roche (Mexico City, Mexico).

Isolation and characterization of 7-ACAG was carried out according to a previously described method (Estrada-Reyes et al., 2004; Martínez-Vázquez et al., 2012). Purity of 7-ACAG was determined using High-performance liquid chromatographyElectrospray-Mass Spectrometry (HPLC-ESI-MS) (Fig. 1) (Estrada-Reyes et al., 2014).

\subsection{Animals}

Adult male Swiss-Webster mice (weighing 20-30 g) and Wistar rats (weighing 150-200 g) were used for
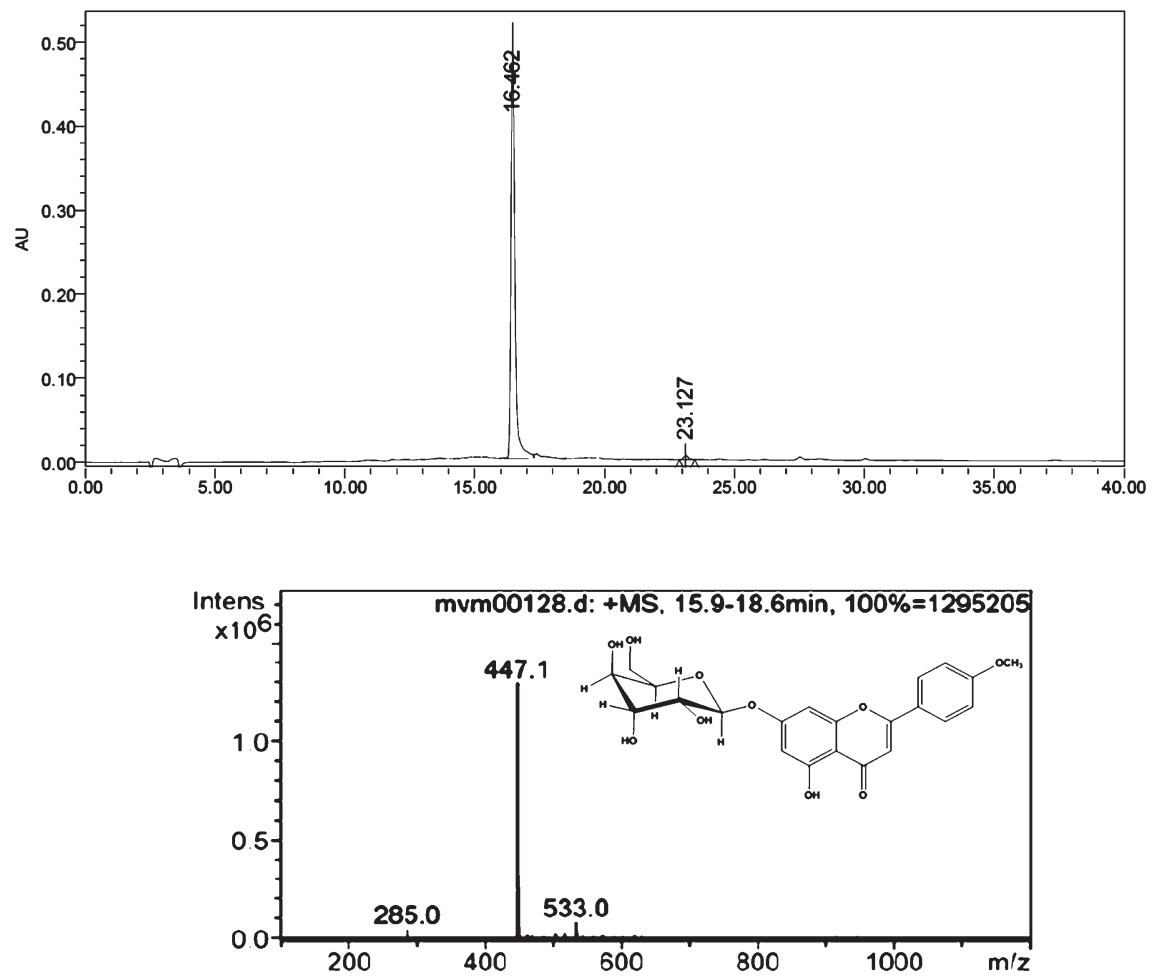

Fig. 1. Chromatography profile and mass spectrum $\left[\mathrm{M}^{+1}\right]$ of Acacetin 7-O-glucoside (7-ACAG). RT: 16.4 min, \% relative area: 99.21 [M $]^{+1}$; $\mathrm{m} / \mathrm{z}$ : 447.12, $\mathrm{C}_{22} \mathrm{H}_{22} \mathrm{O}_{10}$. RT: Retention time; percentage relative of area (purity), $[\mathrm{M}]^{+1}$ : molecular ion plus 1 , m/z mass number/charge number ratio. High-Performance Liquid Chromatography-Electrospray-Mass Spectrometry (HPLC-ESI-MS) profile of Acacetin 7-O-glucoside (7-ACAG). 


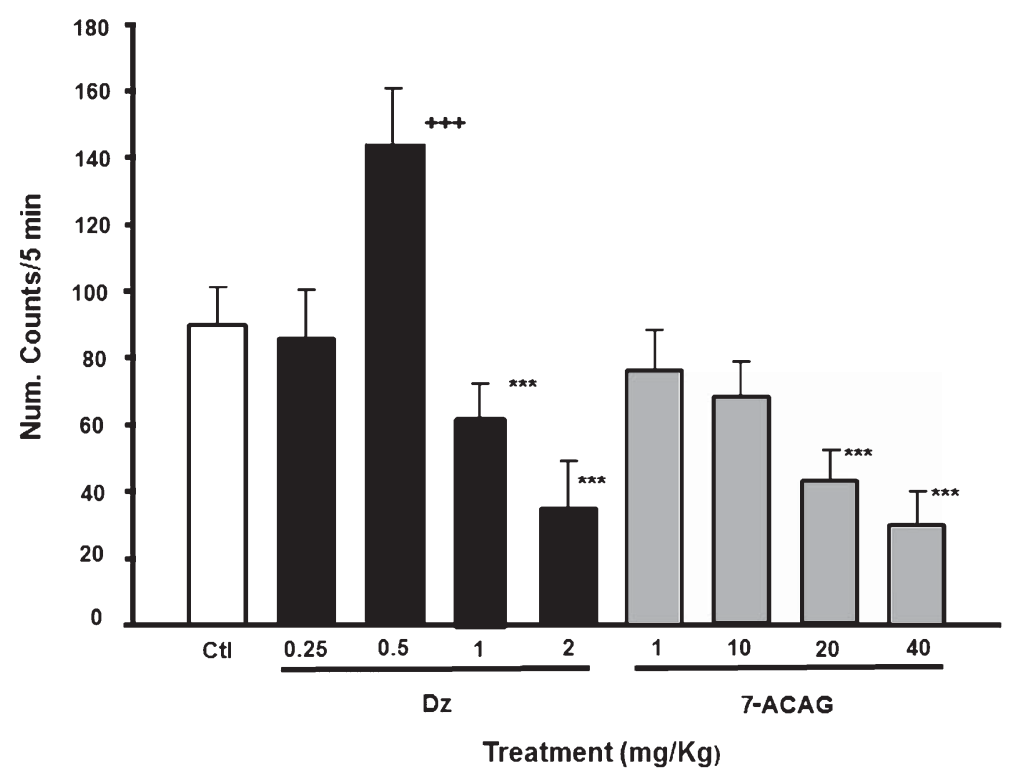

Fig. 2. The effect of the 7-ACAG on ambulatory activity in the Open field test (OFT). Effect of the 7-ACAG on ambulatory activity. All results are expressed as means \pm Standard error of the mean (SEM) of groups of 8-10 animals each. Comparisons were made by using a Kruskal-Wallis one-way Analysis of variance (ANOVA) on ranks, followed by Mann-Whitney $U$ test: ${ }^{*} P \leq 0.05 ;{ }^{* *} p \leq 0.01 ;{ }^{* * *} p \leq 0.001$.

behavioral tests and electrophysiological recording experiments.

For histological analysis, rats weighing 250-300 g were utilized. All rodents were housed in a temperature-controlled $\left(20-21^{\circ} \mathrm{C}\right)$ room under inverted light:dark conditions (12 h:12 h) with lights on at 22:00 h).

Rodents were managed in agreement with general principles of laboratory animal care (Guide for the Care and Use of Laboratory Animals: National Institutes of Health (NIH) publication no. 85-23, revised in $1985)$ and the "Norma Official Mexicana" (NOM-062ZOO-1999). Additionally, the experimental protocol was approved by the local Ethics Committee.

\subsection{Drug administration}

All drugs were intraperitoneally (i.p.) administered in a total volume of $1 \mathrm{ml} / \mathrm{kg}$ and $2 \mathrm{ml} / \mathrm{kg}$ body weight to mice and rats, respectively. 7-ACAG was dissolved in 2\% Dimethyl sulfoxide (DMSO) in saline and independent groups of eight mice each were treated with $1,10,20$, and $40 \mathrm{mg} / \mathrm{kg}, 60 \mathrm{~min}$ prior to the behavioral test. The control group received the same volume of the vehicle. BIC $(80 \mathrm{mg} / \mathrm{kg})$ was administered $60 \mathrm{~min}$ afterward.

\subsection{Behavioral tests in mice}

For habituation, mice and rats received a daily i.p. injection of saline solution $(0.1 \mathrm{ml} / 10 \mathrm{~g})$ for 5 days before treatments. DZ was employed as a reference drug in the sedative test. 7-ACAG doses and latencies were obtained from previous pilot studies. One group of eight animals received DZ (1 or $2 \mathrm{mg} / \mathrm{kg}$ ) $30 \mathrm{~min}$ before the test; this group served as a standard reference. The group receiving only the vehicle served as negative control.

\subsubsection{Hole-board test (HBT)}

The Hole-board test (HBT) set-up apparatus is a wooden box measuring $60 \times 60 \times 30 \mathrm{~cm}$ dimensions, with four equidistant holes ( $2 \mathrm{~cm}$ in diameter) on the floor. The number of Head-dips (HDN) into the holes, the latencies of Head-dipping (HDL), and Rearings number (RN) were recorded over a 5-min period. A decrease in the number of HDL and RN compared with those of the controls were considered to indicate a sedative effect, whereas an increase in these explorative behaviors was considered an anxiolytic effect (Estrada-Reyes et al., 2010). 


\subsubsection{Open field test (OFT)}

The Open field test (OFT) was employed to evaluate ambulatory and exploratory activity. The apparatus consisted of an opaque-Plexiglas ${ }^{\circledR}$ box $(40 \times 30 \times 20 \mathrm{~cm})$ with the bottom of the box divided into 12 equal squares. Each mouse was placed in the center and its behavior was video-recorded during a 5-min session. An observer blinded to the pharmacological treatment administered registered the number of times the animal crossed each square (counts/5min). A count was considered when a mouse crossed a square next to the following one with $100 \%$ of its body. An increased number of counts were considered an anxiolytic-like effect, while a decreased number was considered a sedative effect. The test box was carefully cleaned after each recording (López-Rubalcava et al., 2006; Estrada-Reyes et al., 2012).

\subsubsection{Protective effects on the Bicuculline model}

The presence or absence of clonic seizures, as well as latency to myoclonic and tonic seizures and death latency, was observed for $40 \mathrm{~min}$ following the administration of BIC. The percentage of mice protected from the effects of BIC was quantified. DZ at $1 \mathrm{mg} / \mathrm{kg}$ was utilized as control group.

\subsection{Hippocampal-slice preparation}

Rats were anesthetized and then perfused transcardially with cold, modified artificial Cerebral spinal fluid (CSF, pH 7.4) containing the following (concentrations in $\mathrm{mM}$ ): 229 sucrose; 10 glucose; $26 \mathrm{NaHCO}_{3}$; $1.26 \mathrm{Na}_{2} \mathrm{HPO}_{4}-7 \mathrm{H}_{2} \mathrm{O} ; 2.0 \mathrm{KCl}$, and $1.5 \mathrm{MgCl}_{2}$, bubbled with a mixture of $95 \% \mathrm{O}_{2} / 5 \% \mathrm{CO}_{2}$ (carbogen). Hippocampal sagittal slices of $410 \mu \mathrm{m}$ were incubated for 45-60 min at room temperature in standard CSF containing the following (in $\mathrm{mM}$ ): $125 \mathrm{NaCl}$; 10 glucose; $2 \mathrm{KCl} ; 26 \mathrm{NaHCO}_{3} ; 1.2 \mathrm{Na}_{2} \mathrm{HPO}_{4}-7 \mathrm{H}_{2} \mathrm{O}$; $3 \mathrm{MgCl}_{2}$, and $3 \mathrm{CaCl}_{2}$ bubbled with carbogen at a $\mathrm{pH}$ of 7.4 .

\subsubsection{In vitro measuring of fEPSP of area CA1 in hippocampal slices}

Slices were transferred into a recording chamber maintained at $22 \pm 2{ }^{\circ} \mathrm{C}$ and constantly superfused $(1.5-2 \mathrm{ml} / \mathrm{min})$ with standard CSF. Slice recordings were carried out at $22-25^{\circ} \mathrm{C}$. Synaptic responses and pharmacological effects obtained at $32^{\circ} \mathrm{C}$ are similar to synaptic responses obtained at room temperature. There is no significant difference between experiments carried out at these two different temperatures. However, temperatures of $32^{\circ} \mathrm{C}$ can damage slices when the duration of experiments is long, for this reason temperature of in vitro experiments was set to room temperature. To evoke CA1 field Excitatory Post-Synaptic Potentials (fEPSP), stimulation pulses were applied using orthodromic stimulation with bipolar electrodes placed into Schaffer (axon) collaterals. Stimuli were square wave pulses (duration, $60-100 \mu \mathrm{s} ; 20-70 \mu \mathrm{A}$ ) delivered at $0.08 \mathrm{~Hz}$ for continuous recording (Grass Stimulator Model S48). fEPSP were recorded (AxoClamp 2B amplifier) in the CA1 area using glass micropipettes (4-6 M $\Omega$; Puller flaming brown micropipette MOD p97). Analysis of amplitude and the Paired-pulse (PP) test were carried out with P-clamp ver. 8. To quantify changes, SigmaPlot (ver. 10, Jandel Scientific) and Origin software (ver. 8) were used. Identification of CA1 fEPSP was based on the following criteria: (1) negative waveform; (2) latency (7 ms); (3) medium time course (20 ms), and (4) Paired-pulse inhibition (PPi; 40-50\% at $30 \mathrm{~ms}$ Interstimulus interval, ISI). In previous studies, we established that exposure to the vehicle and stimulation frequency for $120 \mathrm{~min}$ exerted no effect on baseline (fEPSP) (Calixto et al., 2000). Changes in fEPSP slope were expressed in percentages of the mean fEPSP slope recorded during the baseline period. PPi is the relation between the second and first fEPSP slopes (2fEPSP/1fEPSP): if the second fEPSP is lower than the first fEPSP, the relation between these two responses is considered $<1$, this indicating powerful recurrent inhibition (GABAergic activity) identified within a range of $20-60 \mathrm{~ms}$. In vitro recordings of the fEPSP were performed in 10 different and independent groups as follows: Control $(n=7)$; vehicle $(n=5)$ : GABA $3 \mathrm{mM}(n=9) ; 7-\mathrm{ACAG}(50 \mathrm{mg} / 40 \mathrm{ml}$ or $2.8 \mu \mathrm{M}(n=9) ; 75 \mathrm{mg} / 40 \mathrm{ml}$ or $4.1 \mu \mathrm{M} \quad(n=9)$; $100 \mathrm{mg} / 40 \mathrm{ml}$ or $5.6 \mu \mathrm{M}(n=7)$; BIC $(20 \mu \mathrm{M}(n=12)$; $\mathrm{BIC}+\mathrm{GABA}(n=9) ; 7-\operatorname{ACAG}(2.8 \mu \mathrm{M})+\mathrm{BIC}(n=12)$, and vehicle+BIC $(n=7)$.

\subsection{Behavioral Beam balance tests (BBT) and EEG recording in hemiplegic rats}

In brief, in these experiments, rats were subjected to a stereotaxic surgery (phase I) to allow EEG recording. One week later, rats were tested on the Beam balance test (BBT) for 7 days (phase II). Animals that acquired the learning criteria were then subjected to $\mathrm{Hp}$ on day 8 (phase III). One $\mathrm{h}$ or $24 \mathrm{~h}$ after induction of $\mathrm{Hp}$, 
rats were treated either with 7-ACAG or $\alpha$-Tocopherol. Rats were tested again in the BBT under hemiplegic and treatment conditions (phase IV). EGG recording was performed from phases II-IV.

\subsubsection{Phase I) Stereotaxic surgery}

This was performed to place epidural recording electrodes (low impedance) for symmetrical acquisition of the electric signal of the left and right somatomotor cortex ( $1 \mathrm{~mm}$ behind bregma and $3 \mathrm{~mm}$ relative to the mid-line). An indifferent electrode was placed $3 \mathrm{~mm}$ anterior to bregma, according to the Paxinos and Watson Atlas (1998). The active terminal of each electrode was welded to a connector, which permitted the continuity of the bioelectric signal from the electrode to an EEG amplifier (Grass P511). The electrode-connector complex was attached to the skull with acrylic to permit a stable EEG recording and X8EWB identification of electric activity. The signal was acquired and analyzed using PolyVIEW16 software (National Instruments). EEG power, amplitude, and frequency were analyzed using wavelet analysis (frequency, $0-16 \mathrm{~Hz}$ ).

\subsubsection{Phase II) Motor task on the beam balance/beam walking test (BWT)}

One week after stereotaxic surgery, rats were trained for 7 days to walk on an elevated $(30-\mathrm{cm})$, narrow, (2.5$\mathrm{cm}) 2$-m-long wooden beam (mean time, $18 \pm 4.8 \mathrm{~s}$ ). Motivation of rats to run through the beam was to return to the home cage located at the end of the bar. Acquisition learning was considered accomplished on day 7 , when the motor task took $9 \pm 1.5 \mathrm{~s}$ to be performed.

\subsubsection{Phase III) Induction of hemiplegia}

Animals were subjected to a unilateral, right somatomotor cortex lesion as described (Brailowsky et al., 1995). Surgery was performed under barbituric anesthesia. Rats were positioned in a stereotaxic apparatus with the skull horizontal to the platform. A craniotomy was performed from $\mathrm{AP}+2$ to $-4 \mathrm{~mm}$ relative to bregma and $1-5 \mathrm{~mm}$ lateral to midline. After removal of the bone, a flap was made in the dura mater to expose the underlying cortical tissue. A square $(3 \times 3 \mathrm{~mm})$ formed from a wire (diameter, $0.5-\mathrm{mm}$ ) was mounted onto a stereotaxic holder and lowered $2 \mathrm{~mm}$ into the cortex. Once inserted into the brain, the holder was moved in the AP direction for $4 \mathrm{~mm}$ to excise a $3-\mathrm{mm} \times 4$ $\mathrm{mm}$ cortical slab from the somatomotor region of the right cortex. The cortical slab was then weighed. In a
Sham-operated group of rats, the procedure was similar, except that craniotomy was not performed.

\subsubsection{Phase IV) Test on the beam walking/hemiplegia-walking effect}

After surgically induced brain damage, independent animal groups were treated either for 1 or $24 \mathrm{~h}$ as follows: Vehicle $(n=5)$; 7-ACAG $(20 \mathrm{mg} / \mathrm{kg}, 1 \mathrm{~h}$ : $n=12 \mathrm{~h}$, or $24 \mathrm{~h}: n=19)$, or $\alpha$-Tocopherol $(20 \mathrm{mg} / \mathrm{kg} ; 1$ h: $n=9 \mathrm{~h}$, or $24 \mathrm{~h}: n=11)$. These treatments were compared with the control group $(n=10)$. Chronic EEG was recorded and functional motor recovery was evaluated by applying the Beam walking test (BWT) again for 1 week. Performance was measured in terms of time (s) employing mean walking time prior to (3 rounds) and after (3 rounds) the induction of $\mathrm{Hp}$.

\subsection{Histological analysis}

Animals were administered an overdose of pentobarbital and transcardially perfused with $0.1-\mathrm{M}$ Phosphate buffered saline (PBS) solution and a $4 \%$ paraformaldehyde solution. Brains were post-fixed for 1 week at $4{ }^{\circ} \mathrm{C}$ and processed for embedding in paraffin. Coronal sections were then cut (12- $\mu$ m thickness) with a microtome (Leica RM2125 RT; Germany) and processed for Nissl staining. Neurons in the somatomotor cortex and in the CA1 area of the ipsilateral area to Hp were counted with an optic microscope (Carl Zeiss AxioLab) adapted to Image Pro-Plus ver. 5.1 software. Number of neurons was quantified using the factionary steps method (West et al., 1993), which consists of dividing the neuron number determined in a specific volume fraction by the number of sections.

\subsection{Statistical analysis}

Data obtained from mice on behavioral tests did not meet normality or variance equally criteria (number of subjects, representative traces, normal distribution and homogeny of variance). Differences between treated and control groups in the behavioral tests were analyzed using a Kruskal-Wallis analysis of variance on ranks $\left({ }^{*} P \leq 0.05,{ }^{* *} p \leq 0.01\right.$, and $\left.{ }^{* * *} p \leq 0.001\right)$ followed by the Mann-Whitney Rank Sum test. Data obtained from experiments in vitro were analyzed using parametric analyzes. Statistical significance of changes in the slope of fEPSP was assessed by means of paired and unpaired Student $t$ tests and Analysis of variance (ANOVA) (relation between control, 
7-ACAG, GABA, and Bicuculline (BIC) groups). If necessary, Bonferroni's correction factor was applied to avoid a combined level of $>0.05$. All statistical analyses and graphics were carried out using the SigmaStat (ver. 3.5, Jandel Scientific) and SigmaPlot (ver. 10, Jandel Scientific) statistical software programs, respectively.

\section{Results}

\subsection{Purity}

7-ACAG purity was $99.21 \%$, which was determined by High-performance liquid chromatography-Mass spectrometry (HPLC-MS) analysis (Fig. 1).

\subsection{Behavioral mouse tests}

The effects of aqueous extracts of A. mexicana subsp. mexicana and xolocotziana were characterized as anxiolytic-like and sedative in mouse. However, the effects of 7-ACAG, one the main secondary metabolites of these extracts, are unknown. Table 1 depicts the effects of either DZ $(2 \mathrm{mg} / \mathrm{kg}$ ) or 7-ACAG $(1,10,20$, and $40 \mathrm{mg} / \mathrm{kg})$ on mouse performance in the HBT. DZ was employed as positive control. Both treatments significantly decreased the number of head-dippings $(\mathrm{H}=42.08, \mathrm{fd}=5,=5, p \leq 0.001)$ $(\mathrm{fd}=$ freedom degree $)$ and time $(H=14.40, \mathrm{fd}=5$, $p \leq 0.01$ ), as well as the Rearings number (RN) $(\mathrm{H}=55.58, \mathrm{fd}=5, p \leq 0.001)$. The sedative effect of 7 -ACAG was confirmed in the OFT. DZ $(0.5 \mathrm{mg} / \mathrm{kg})$ produced a significant increase in the spontaneous locomotion activity of the mice. Doses ranging from $1-2 \mathrm{mg} / \mathrm{kg}$ significantly reduced mouse ambulatory counts, while administration of 7-ACAG gave rise to a decrease in spontaneous ambulatory activity in a dose-dependent manner $(\mathrm{H}=64.42, \mathrm{fd}=8, p \leq 0.001)$ (Archer et al., 1973; Walsh \& Cummins, 1976) (Fig. 2).

As illustrated in Table 2, in the BIC model, neither DZ $(1 \mathrm{mg} / \mathrm{kg})$ nor 7-ACAG at the doses tested avoided the appearance of seizures. However, 7-ACAG at 20 and $40 \mathrm{mg} / \mathrm{kg}$ delayed the onset of BIC-induced seizures $(p \leq 0.05)$, and at $40 \mathrm{mg} / \mathrm{kg}$ delayed the appearance of both myoclonic and tonic seizures. In contrast, DZ produced a delay in the latency of tonic seizures, but did not modify their onset. Furthermore, 7 -ACAG reduced the percentage of death up to $28 \%$, while DZ produced a reduction of $50 \%$. The data shown here suggest the involvement of the GABAergic system in 7-ACAG effects.

\subsection{Electropharmacological effects of 7-ACAG in hippocampal slices}

To determine the involvement of the GABAergic system in 7-ACAG effects, hippocampal slices were incubated with the flavonoid and electrophysiological responses were registered. To avoid saturation of the response's maximal increase, stimulation was adjusted from 50 to $60 \%$ of the maximal response, nearly 1.7-2.1 times the threshold value. Stimulation amplitude was maintained during the whole experiment and did not induced changes in amplitude or PPi during any control experiment. To reduce glutamate activity,

Table 1

Effect of 7-ACAG on the performance of mice in the Hole-board test (HBT)

\begin{tabular}{lccc}
\hline Treatment $(\mathrm{mg} / \mathrm{kg})$ & HDT/5 min & RN/5 min & HDN/5 min \\
& Mean \pm SEM & Mean \pm SEM & Mean \pm SEM \\
\hline Control & $0.44 \pm 0.12$ & $27.7 \pm 2.23$ & $36 \pm 2.39$ \\
7-ACAG 1 & $0.66 \pm 0.04$ & $22.25 \pm 0.7^{* *}$ & $28.44 \pm 2.1^{* *}$ \\
7-ACAG 10 & $0.32 \pm 0.09^{*}$ & $14.12 \pm 1.5^{* * *}$ & $21.11 \pm 1.6^{* * *}$ \\
7-ACAG 20 & $0.19 \pm 0.04^{* *}$ & $9.88 \pm 1.9^{* * *}$ & $23.00 \pm 3.0^{* * *}$ \\
7-ACAG 40 & $0.12 \pm 0.05^{* * *}$ & $2.77 \pm 0.5^{* * *}$ & $17.88 \pm 2.3^{* * *}$ \\
\hline DZ 2.0 & $0.30 \pm 0.13^{*}$ & $17.12 \pm 1.7^{*}$ & $22.6 \pm 1.91^{* * *}$ \\
\hline & $\mathrm{H}=14.40, \mathrm{fd}=5$ & $\mathrm{H}=55.58, \mathrm{fd}=5$ & $\mathrm{H}=42.08, \mathrm{fd}=5$ \\
& $(p \leq 0.006)$ & $(p \leq 0.001)$ & $(p \leq 0.001)$ \\
\hline
\end{tabular}

Effect of 7-ACAG on sedative behavior [Head-dipping time/5 min (HDT), Rearings number/5 min (RN), and Headdipping number/5 min (HDN)]. All results were expressed as means \pm Standard error of the mean (SEM) of groups of 8-10 animals each; $\mathrm{fd}=$ field distance. Comparisons were made using a Kruskal-Wallis one-way Analysis of variance (ANOVA) on ranks, followed by the Mann-Whitney $U$ test: ${ }^{*} P \leq 0.05 ;{ }^{* *} p \leq 0.01 ;{ }^{* * *} p \leq 0.001$. 
Table 2

Effect of 7-ACAG and Diazepam (DZ $=1 \mathrm{mg} / \mathrm{kg})$ on seizures induced by Bicuculline (BIC) $(45 \mathrm{mg} / \mathrm{kg})$ in mice

\begin{tabular}{|c|c|c|c|c|}
\hline \multirow[t]{2}{*}{ Treatment $(\mathrm{mg} / \mathrm{kg})$} & \multicolumn{2}{|c|}{ Seizure onset \pm SEM (s) } & \multirow[t]{2}{*}{ Death latency } & \multirow[t]{2}{*}{ Percentage of mortality } \\
\hline & Myoclonic & Tonic & & \\
\hline Control & $116.5 \pm 6.0$ & $127 \pm 5.5$ & $388.1 \pm 13.9$ & 100 \\
\hline DZ 1 & $114.71 \pm 9.4$ & $201 \pm 8.7^{* *}$ & $453 \pm 27.6$ & 57.14 \\
\hline 7-ACAG 1 & $101.1 \pm 4.8$ & $130.8 \pm 15.0$ & $380.5 \pm 17.3$ & 100 \\
\hline 7-ACAG 10 & $121.0 \pm 14.3$ & $134.5 \pm 11.2$ & $350.4 \pm 29.9$ & 100 \\
\hline 7-ACAG 20 & $138.7 \pm 16.3^{*}$ & $147.7 \pm 18.0$ & $446 \pm 25.5$ & 72 \\
\hline 7-ACAG 40 & $175.8 \pm 5.7^{* * *}$ & $181.28 \pm 6.1^{* * *}$ & $499 \pm 11.5$ & 28.5 \\
\hline
\end{tabular}

$\mathrm{H}=16.81, \mathrm{df}=5, p=0.005 \quad \mathrm{H}=15.85, \mathrm{df}=5, p=0.007 \quad \mathrm{H}=22.40, \mathrm{df}=5, p \leq 0.001$

Effect of 7-ACAG on Bicuculline (BIC)-induced seizures ( $45 \mathrm{mg} / \mathrm{kg}$; intraperitoneally, i.p.). Data represent means \pm Standard error of the mean (SEM) of seven animals. Comparisons were made by using Kruskal-Wallis one-way Analysis of Variance (ANOVA) on ranks followed by the Mann-Whitney $U$ test: ${ }^{*} P \leq 0.05,{ }^{* *} p \leq 0.01$, and ${ }^{* * *} p \leq 0.001$ compared with the control group.
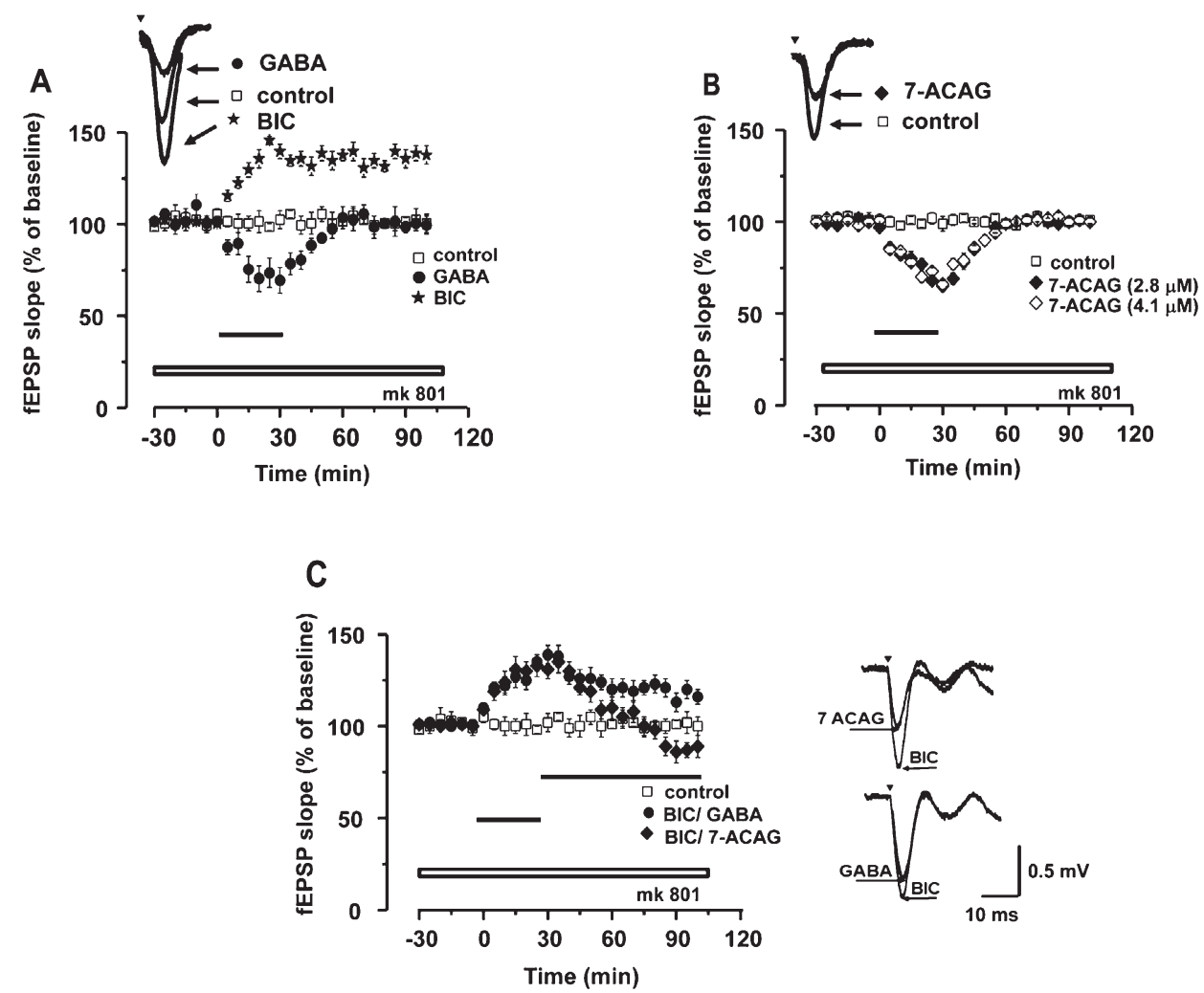

Fig. 3. 7-ACAG and its possible GABAergic activity in hippocampal slices. Temporal course of evoked field Excitatory Post-synaptic Potentials (fEPSP) amplitude during $2 \mathrm{~h}$ of recording. Data group (mean \pm Standard error of the mean [SEM]) of the fEPSP slope before, during, and after drug exposure. Horizontal bars indicate time of drug superfusion $(30 \mathrm{~min})$, while the $\log$ bar indicates that all experiments were carried out in the presence of MK801 (5 mM) (Representative traces; calibration: $0.5 \mathrm{mV}: 10 \mathrm{~ms}$ ). A) Gamma-Aminobutyric acid (GABA) (3 mM; black circles) reduces the synaptic response; this effect is reversible. Bicuculline (BIC) $(20 \mu \mathrm{M}$; black stars) induces long-lasting hyperexcitability. B) Application of 7-ACAG at two different concentrations $(2.8 \mu \mathrm{M}$; black rhombus, and $4.1 \mu \mathrm{M}$; white rhombus) exerts a reversible decreasing effect on the synaptic response slope of the CA1 area. C) GABA administration decreases the hyperexcitability effect induced by BIC (black circles). Moreover, application of 7-ACAG blocked this same hyperexcitability effect.

all experiments were carried out in the presence of MK801 ( $5 \mathrm{mM})$, an inhibitor of the $N$-methyl-D-aspartate (NMDA) receptor. GABA incubation at $3 \mathrm{mM}$ induced a transitory decrease of the synaptic response (Fig. 3A. black circles; reduction of the slope $31 \%$ ) and displaced the Input/Output (I/O) curve to the right, 
A

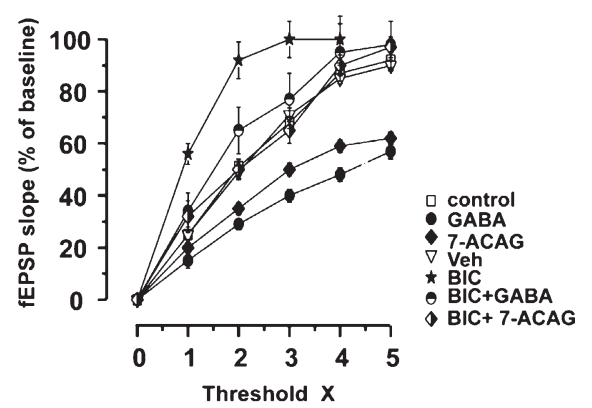

B

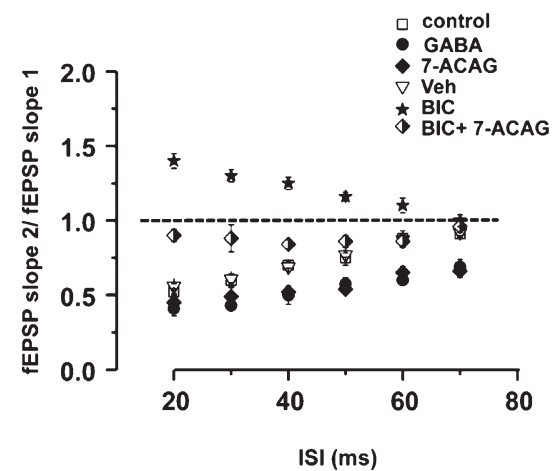

C

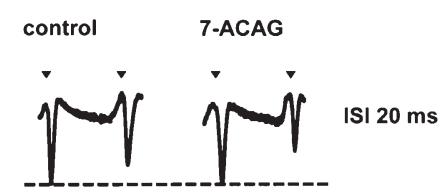

BIC

$B I C+7-A C A G$

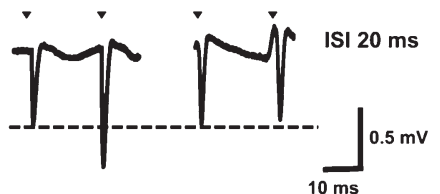

Fig. 4. 7-ACAG increases Paired-pulse (PP) inhibition and reduces the Bicuculline (BIC) hyperexcitability effect. A) The control Input/Output curve (I/O; white squares) illustrates that the increase of the synaptic responses (field Excitatory Post-synaptic Potentials, fEPSP) of the CAI area is proportional to the increase of the synaptic stimulation. Threshold is defined as the initial response from which negative amplitude is obtained and that increases by $100 \%$, five times the initial threshold value. Exposure to 7-ACAG (black rhombus) displaces the I/O curve to the right; similar results are obtained from application of GABA (black circles). BIC displaces the I/O curve to the left (black star). Application of GABA (white/black circles) or 7-ACAG (white/black rhombus) reduces the increase of hyperexcitability induced by BIC. The vehicle has no effect (white triangles). B) The delivery of two pulses with identical intensity and with Inter-stimuli intervals (ISI) $<60 \mathrm{~ms}$ (ISI) causes the decrease in the amplitude of the second fEPSP. The relation between control slopes (fEPSP2/fEPSP1) (mean \pm Standard error of the mean $[\mathrm{SEM}]$ ) is depicted in white squares. 7-ACAG increases Paired-pulse inhibition (PPi) (black rhombus). The GABA effect (3 mM) is illustrated in black circles. The vehicle does not modify the PPi. Bicuculline (BIC) facilitates Paired-pulse (PP) in CA1 area (black stars); however, 7-ACAG significantly blocks the powerful hyperexcitability effect of BIC (white/black rhombus; $p \leq 0.001$ ). C) Representative synaptic responses at ISI $20 \mathrm{~ms}$ with increased slope induced by BIC and overlying fEPSP that depict the effects of the application of 7-ACAG (upper panel) and BIC+7-ACAG (lower panel). Calibration: $0.5 \mathrm{mV} ; 10 \mathrm{~ms}$.

indicating a decrease in the sensitivity of the tissue to electric stimulation (Fig. 4A; black circles) and an increase of the PPi in 20\% (Fig. 4B; black circles). In contrast, the use of an antagonist of the $\mathrm{GABA}_{\mathrm{A}}$ receptor, such as BIC, increases excitability (Fig. 3A; increase of the slope in 46\%), displaces the InputOutput (I/O) curve to the left (Fig. 4A; black stars), and induces PP facilitation $1.4 \pm 0.05$ at ISI $20 \mathrm{~ms}$ (Fig. 4B and C; black stars). The effects of 7-ACAG on the CA1 hippocampus-area synaptic response were tested at $2.8,4.1$, and $5.6 \mu \mathrm{M}$ in independent groups of brain slices.

In the presence of $2.8 \mu \mathrm{M}$ of 7 -ACAG superfusion, the fEPSP slope in the CA1 hippocampal area decreased by $35 \%$ (Fig. 3B; black rhombus at $30 \mathrm{~min}$ of incubation; $p \leq 0.01)$. This effect was transitory because, during the washing period, the synaptic responses recovered baseline values. Brain slices incubated with increased $7-A C A G$ concentrations $(4.1 \mu \mathrm{M})$ exhibited a $34 \%$ decrease in the slope of the synaptic response (Fig. 3B; white rhombus). Similar results were obtained at a higher 7-ACAG concentration $(5.6 \mu \mathrm{M}$ ): the fEPSP slope decreased by $28 \%$ (data not shown). These effects were transitory. The 7-ACAG concentration utilized in subsequent experiments was set at $2.8 \mu \mathrm{M}$.

After 30 min of 7-ACAG incubation, the I/O curve test was applied. The curve demonstrated displacement 
to the right (a similar effect is produced by administration of GABA), this meaning a decrease of synaptic excitability produced by a possible increase of inhibitory activity (Fig. 4A; black rhombus; $p \leq 0.01$ between $2-5$ threshold). To identify the involvement of GABAergic neurotransmission in the 7-ACAG effect at synaptic level in hippocampal area CA1, a Paired-pulse (PP) stimulation protocol was elaborated. Under these conditions, the PP protocol showed that 7-ACAG induced powerful inhibition in the slope of the second fEPSP between 20 and $70 \mathrm{~ms}$. This electropharmacological effect on the increase in recurrent inhibition is similar to that induced by GABA (Fig. 4A and B; black circles; $p \leq 0.01$ ).

To characterize the effect of 7-ACAG on GABAergic responses in hippocampal area CA1, 7-ACAG was administered after BIC $(20 \mu \mathrm{M})$. Administration of BIC increased the slope of the synaptic response by $146 \%$ (Fig. 3A), while 7-ACAG at $2.8 \mu \mathrm{M}$ after BIC application significantly reduced the slope by $87 \%$ with regard to baseline values (Fig. 3C; black rhombus; $p \leq 0.01$ ). The data showed that 7-ACAG significantly reduced the BIC excitatory process, similarly to GABA, which decreased the synaptic response (Fig. 3C; black circles). The data suggest that 7-ACAG increases the GABAergic response.

\subsection{7-ACAG positive effect on rats with neuronal damage induced by hemiplegia}

$\mathrm{GABA}_{\mathrm{A}}$ plays an important role in stroke motor recovery (Kim et al., 2014). To study the protective effects of 7-ACAG on $\mathrm{Hp}$, functional recovery was measured by using the Beam walking test (BWT). All rats $(n=61)$ learned the motor task (Fig. 5; white squares; mean time of day $1: 19.3 \pm 1.3 \mathrm{~s}$ compared with mean time of day 7:7.9 $\pm 0.73 \mathrm{~s}$; descendant slope). Time spent on the motor task was not reduced after day 7. Hp rats spent $15.8 \pm 0.57 \mathrm{~s}$ with an $83 \%$ deficit (Fig. 5; group Hp; $n=9 ; p \leq 0.01$ ) on the BWT and with slight recovery during the following days. Three days after Hp induction, rats spent $13.2 \pm 0.6 \mathrm{~s}$ on the beam. Seven days after this, the rats spent $11.6 \pm 0.18 \mathrm{~s}$, that is, a $41 \%$ deficit with respect to their own execution.

Motor task results of rats administered with the vehicle are presented in Fig. 5. Vehicle treatment (white

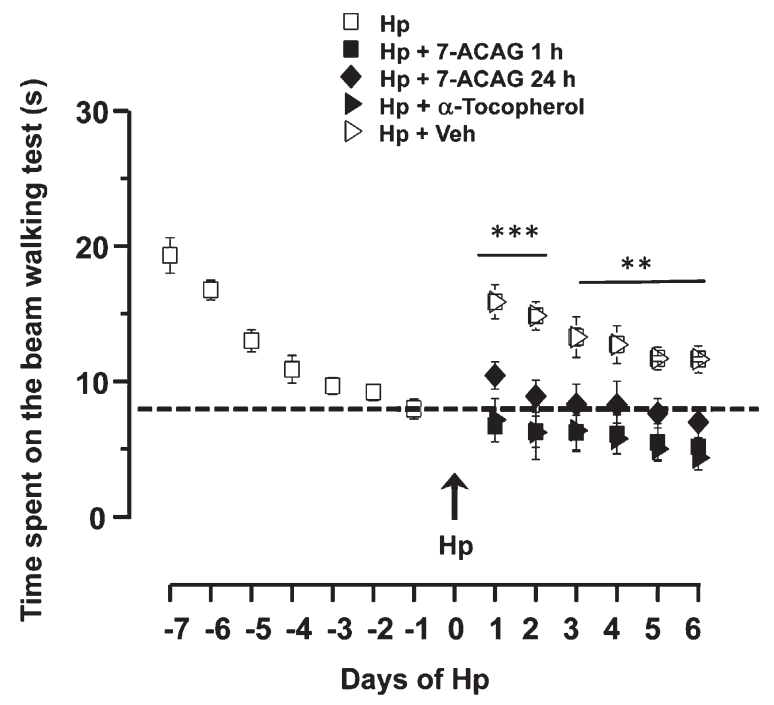

Fig. 5. Application of 7-ACAG increases the functional recovery of rats with motor deficit induced by hemiplegia. Temporal evolution of time spent on the Beam walking test (BWT). Results are the mean \pm Standard error of the mean (SEM). Rats learned the task in 7 days. On day 8, rats were submitted to Hemiplegia (Hp) and a significant motor deficit was observed. Recovery slope is shown in white squares. 7-ACAG administered either $1 \mathrm{~h}$ (black squares) or $24 \mathrm{~h}$ (black rhombus) after Hp induction significantly decreases motor deficit. $\alpha$-Tocopherol applied $1 \mathrm{~h}$ after Hp induction exhibits similar results to those induced by 7-ACAG. The vehicle had no positive effects on the motor deficit caused by $\mathrm{Hp}$ (white triangles).

triangles) had null impact on the motor task performance caused by Hp. A slight recovery was quantified and no significant differences were observed in $\mathrm{Hp}$ rats (ANOVA; $p \leq 0.1$ ). Rats demonstrated a $33 \%$ deficit in the motor task at 1 week of Hp induction.

Protective effects of 7-ACAG were evaluated by measuring beam walking performance under Hp conditions. Rats administered with 7-ACAG $1 \mathrm{~h}$ after $\mathrm{Hp}$ induction demonstrated fast and stable recovery (Fig. 5; black square; $\mathrm{Hp}+7-\mathrm{ACAG} 1 \mathrm{~h}$ ) and rapid, significant reacquisition of mean time spent on the beam prior to HP-associated neural damage $(p \leq 0.01)$ : 1 day after administration of 7-ACAG, rats spent $7.16 \pm 1.6 \mathrm{~s}$ on the task; in comparison, 1 week after brain damage, rats spent $4.38 \pm 0.9 \mathrm{~s}$ on the beam $(p \leq 0.05)$.

To explore the effects of late treatment initiation, an independent group of rats was administered 7-ACAG $24 \mathrm{~h}$ after Hp (Fig. 5; black rhombus; Hp+ 7-ACAG $24 \mathrm{~h})$. This group of animals exhibited recovery of mean time for performing the BWT (Fig. 5; black 
rhombus); rats spent $10.4 \pm 1 \mathrm{~s}$ on performing the task 1 day after 7-ACAG administration. In contrast, 1 week after 7-ACAG treatment, rats spent $6.9 \pm 1.1 \mathrm{~s}$ on the beam. Significant differences were found in comparison with the control group ( $p \leq 0.05)$.

$\alpha$-Tocopherol administered $24 \mathrm{~h}$ after Hp induction increased functional recovery (Fig. 5; black triangles; $\mathrm{Hp}+\alpha$-Tocopherol), similar to the effects produced by 7-ACAG. Time lapse on the beam was not significantly different $(8.1 \pm 0.5 \mathrm{~s}$ at $24 \mathrm{~h}$ after $\mathrm{Hp}$ in relation to $7.7 \pm 0.8 \mathrm{~s} 7$ days after $\mathrm{Hp}$ ). These data are significant compared with the control group $(p \leq 0.05)$, while no significance was found between $\alpha$-Tocopherol and 7-ACAG treatments $(p \leq 0.5)$.

\subsection{Electrophysiological changes induced by hemiplegia and 7-ACAG effects}

To complement data of the Hp-induced behavioral changes, the relationship between the effects of functional recovery with EEG activity was analyzed. Normal EEG activity is commonly analyzed in the spectrum ranging from $1-12 \mathrm{~Hz}$. However, hyperexcitability occuring in the range increases from 1-20 Hz.

The power of the EEG activity of the wounded right brain cortex of rats subjected to $\mathrm{Hp}$ was not modified. Values obtained prior to $\mathrm{Hp}$ had a mean power of $358 \pm 48 \mu \mathrm{V}^{2} / \mathrm{Hz}$ (Fig. 6B, lower panel; Right cortex; white squares). In contrast, the hemisphere

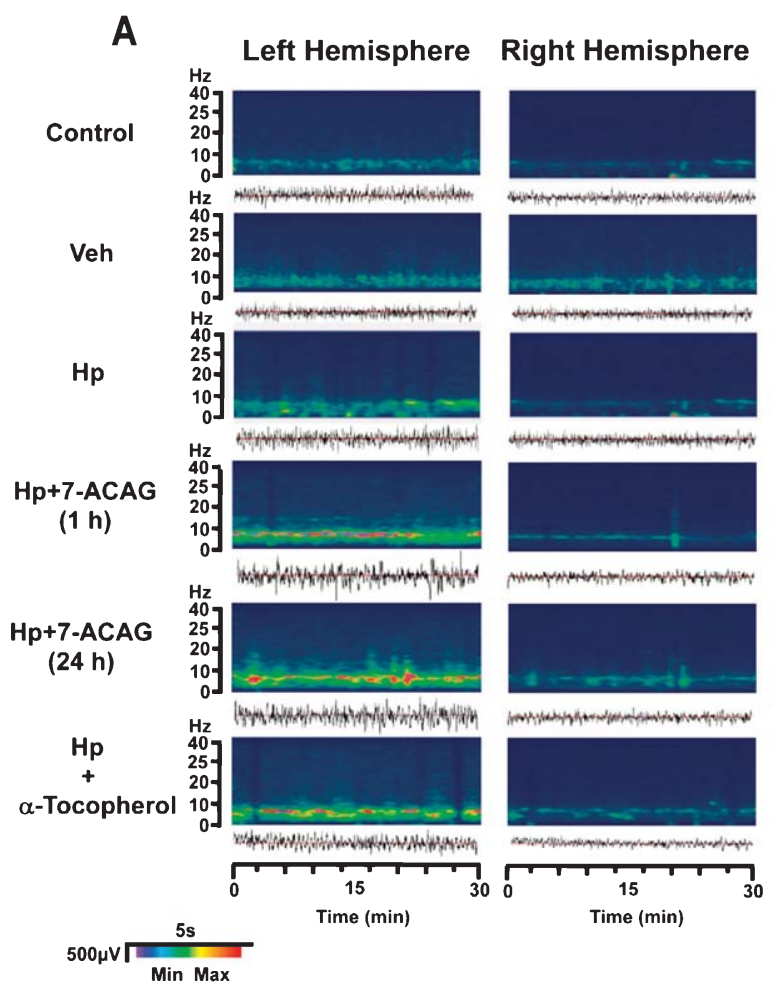

B
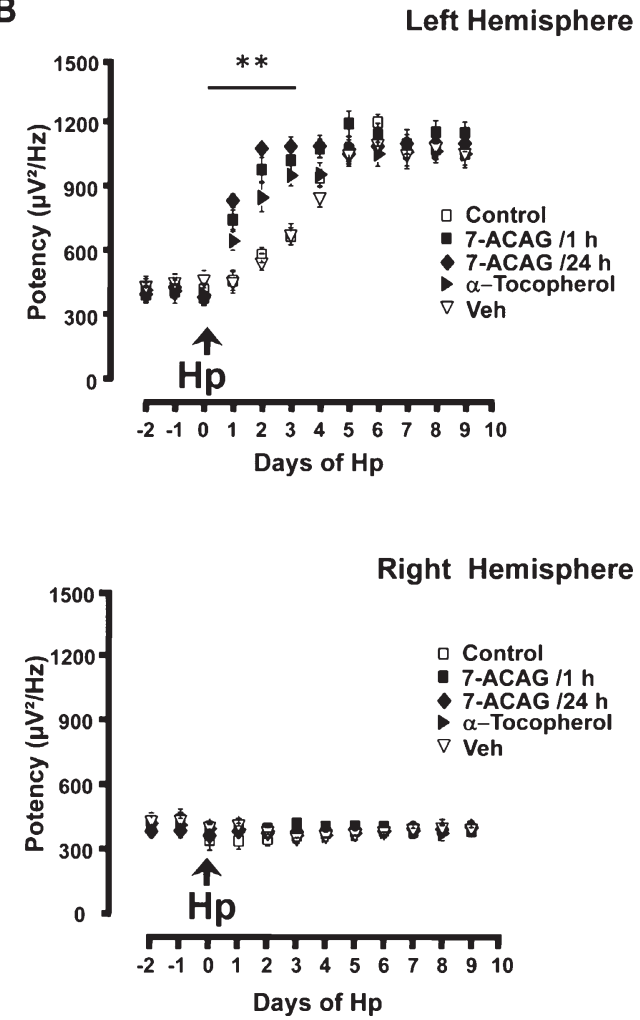

Fig. 6. 7-ACAG applications increase the Electroencephalographic (EEG) power of the brain hemisphere contralateral to the damage. A) Wavelet analysis $(0-40 \mathrm{~Hz} ; 30 \mathrm{~min})$. The presence of red color indicates an increase of EEG amplitude and frequency. Below the panels, representative EEG recordings are shown. Analysis and recordings were obtained $24 \mathrm{~h}$ after Hp induction. 7-ACAG applied $1 \mathrm{~h}$ after Hemiplegia (Hp) induction significantly increased EEG power in the contralateral hemisphere $(p \leq 0.001)$. Similar results were obtained from the group administered 7 ACAG $24 \mathrm{~h}$ after Hp induction. $\alpha$-Tocopherol administered $1 \mathrm{~h}$ after Hp also increased EEG activity in the left hemisphere. B) Temporal evolution before and after Hp. Each point represents the 30-min mean power of the EEG $\left(\mu \mathrm{V}^{2} / \mathrm{Hz}\right) \pm$ Standard error of the mean [SEM]) 2 days prior to and 10 days after Hp. Information in the inferior panel shows that the damaged hemisphere does not modify its EEG activity in the course of 10 days. (Analyses of the contralateral hemisphere exhibit a gradual and constant increase of activity; upper panel). These data are significant 3 days after $\mathrm{Hp}$ induction. Activity reaches its maximal potency 5 days after Hp induction (white squares). Treatment either with 7-ACAG $1 \mathrm{~h}$ after Hp (black squares) or $24 \mathrm{~h}$ after Hp (black rhombus) or $\alpha$-Tocopherol (applied $24 \mathrm{~h}$ after Hp; black triangles) speed the left-hemisphere activation process. The vehicle does not induce changes (white triangles). 
contralateral to the damage had a mean power of $437 \pm 35 \mu \mathrm{V}^{2} / \mathrm{Hz}$. A gradual increase was recorded after $\mathrm{Hp}$ and was significant at day 2. After brain damage, EEG power increased from $624 \pm 35 \mu \mathrm{V}^{2} / \mathrm{Hz}$ (day 2) to $1,144 \pm 46 \mu \mathrm{V}^{2} / \mathrm{Hz}$ (day 7) in the $1-20-\mathrm{Hz}$ spectrum. This implies that $\mathrm{Hp}$ did not induce changes in the EEG power of the wounded hemisphere, but significantly increased contralateral activity by $261 \%$ (Fig. 6A; $p \leq 0.01$ ).

7-ACAG administered $1 \mathrm{~h}$ after $\mathrm{Hp}$ induction decreased activation latency in the contralateral hemisphere. The left brain hemisphere exhibited a significant increase of activity after 1 day of brain damage and the potency amplitude was $789 \pm 45 \mu \mathrm{V}^{2} / \mathrm{Hz}$ in a range of $1-20 \mathrm{~Hz}$ (from a gain of 180 to $260 \%$ at day 3 ). This value was maintained for 1 week (Fig. 6B; black squares). In contrast, the right hemisphere did not demonstrate either immediate or long-term changes as a consequence of 7-ACAG application. Similar results were obtained with the administration of either 7-ACAG $24 \mathrm{~h}$ after $\mathrm{Hp}$ or of $\alpha$-Tocopherol, which induced high activity in the left hemisphere 1 day after Hp induction. The left hemisphere exhibited an increase of $159 \%$ in EEG power: $689 \pm 45 \mu \mathrm{V}^{2} / \mathrm{Hz}$ (Fig. 6B; black rhombus for 7-ACAG/24 h and black triangles for $\alpha$-Tocopherol). No changes were appreciated in right hemisphere power. Application of the vehicle did not produce immediate effects in the contralateral hemisphere. Temporal evolution of the activity did not change compared with the control activity.

\subsection{Protective effects of 7-ACAG}

To explore whether 7-ACAG protected brain cytoarchitecture against the damage caused by $\mathrm{Hp}$, neuron counting was assessed in the CA1 hippocampal region and right somatomotor cortex of rats treated with either the vehicle or with 7-ACAG.

In the control group (intact rats), left and right hippocampal area CA1 demonstrated a mean neuronal density of 7,325 $\pm 152 \mathrm{~mm}^{3}$, while in the Hp group, a $61 \%$ decrease in neuron number in the CA1 hippocampal area (ipsilateral to the hemiplegic hemisphere) was observed $\left(2,821 \pm 87\right.$ neurons $\left./ \mathrm{mm}^{3}\right)$. Similarly, hemiplegic rats treated with the vehicle showed a decreased number of neurons $(2,795 \pm 198)$ (Fig. 7A and B). Rats treated with 7-ACAG $1 \mathrm{~h}$ after induction of $\mathrm{Hp}$ demonstrated a mean of $4,547 \pm 79$ neurons $/ \mathrm{mm}^{3}$, suggesting that damage was reduced by $38 \%$ compared with rats of the control group $(p \leq 0.01)$. Also, histological analysis of brains of rats administered 7-ACAG $24 \mathrm{~h}$ after $\mathrm{Hp}$ demonstrated reduced loss of neurons $\left(5,010 \pm 110\right.$ neurons $\left./ \mathrm{mm}^{3}\right)$. Similar effects were obtained in the CA1 region with the application of $\alpha$-Tocopherol: $4,685 \pm 114$ neurons $/ \mathrm{mm}^{3}$.

In the somatomotor cortex, neuronal density in the Hp group treated with 7-ACAG was similar to that quantified in the control (intact) group (Fig. 7C and D), which showed, in left somatomotor cortex, a neuronal density of $6,950 \pm 121$ neurons $/ \mathrm{mm}^{3}$, while $\mathrm{Hp}$ rats exhibited a decrease of $54 \%$ in neuronal density in right brain cortex $\left(3,190 \pm 95\right.$ neurons $\left./ \mathrm{mm}^{3}\right)$. Neuronal density in somatomotor cortex of rats treated with7-ACAG for either $1 \mathrm{~h}$ or $24 \mathrm{~h}$ after induction of $\mathrm{Hp}$ was $6,150 \pm 88$ and $6,225 \pm 109$ neurons $/ \mathrm{mm}^{3}$, respectively. The decrease in neuronal number was 12 and $10 \%$, respectively, and was significantly different from that observed in $\mathrm{Hp}$ rats $(p<0.05)$. Application of $\alpha$-Tocopherol $1 \mathrm{~h}$ after Hp induction also reduced the decrease in neuronal number in somatomotor left cortex $\left(6,387 \pm 114\right.$ neurons $\left./ \mathrm{mm}^{3}\right)$ caused by Hp, while in vehicle-treated $\mathrm{Hp}$ rats, neuronal density was $3,279 \pm 126$ neurons $/ \mathrm{mm}^{3}$.

\section{Discussion}

In this study, we isolated 7-ACAG from Agastache mexicana subsp. mexicana and xolocotziana, plants commonly used as sedatives, hypnotics, and anxiolytics and for their tranquilizing properties in traditional Mexican medicine. In previous studies, the aqueous extracts of these plants were characterized by their CNS-depressant effects (Estrada-Reyes et al., 2014). In this study, we isolated one of the main constituent of these extracts, 7-ACAG, and characterized its sedative and ambulatory activity effects on behavioral models and on BIC-induced seizures in mice and, in addition, the functional protection of 7-ACAG effects on the Hp stroke rat model in the BWT in rats and, in vitro, hippocampal slices to explore the involvement of the GABAergic system in its actions. The results showed that administration of 7-ACAG to mice produced a clear sedative effect. In addition, 7-ACAG at $20-40 \mathrm{mg} / \mathrm{kg}$ exerted sedative effects similar to those induced by DZ at $12 \mathrm{mg} / \mathrm{kg}$ evaluated on the HBT and OFT. The CNS inhibitory effect of 7-ACAG was demonstrated because a single administration of this compound exhibited partial protection against 
A

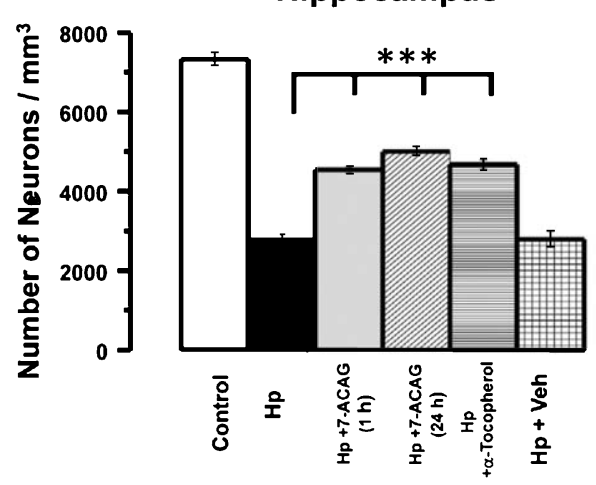

C

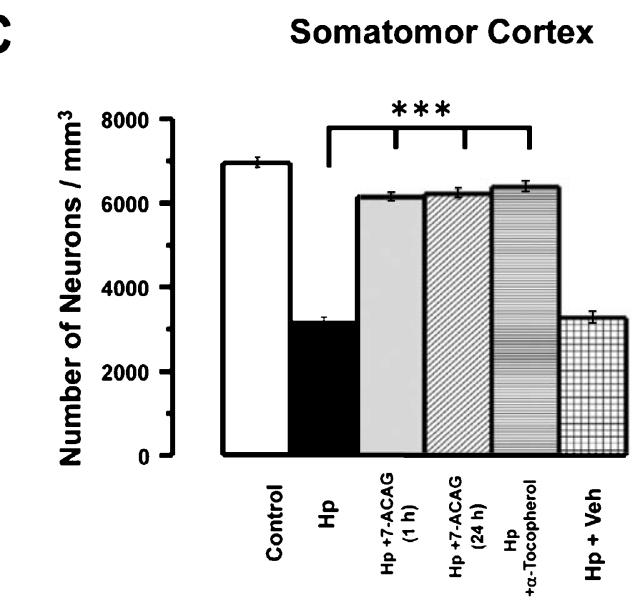

B

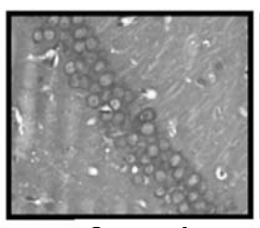

Control

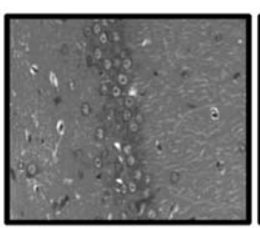

Hp +7-ACAG (24 h)

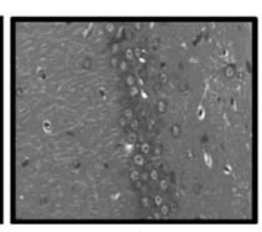

Hp

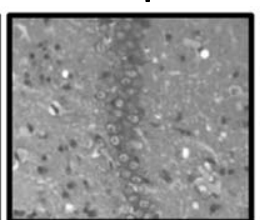

$\mathrm{Hp}+$

$\alpha$-Tocopherol

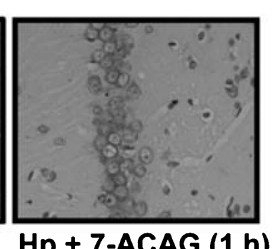

Hp + 7-ACAG (1 h)

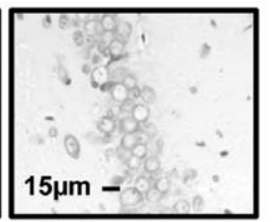

$H p+$ Veh

D

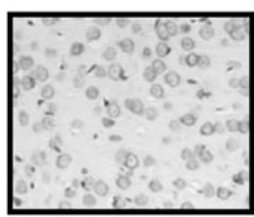

Control

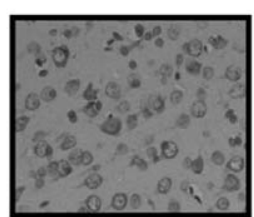

Hp +7-ACAG (24h)

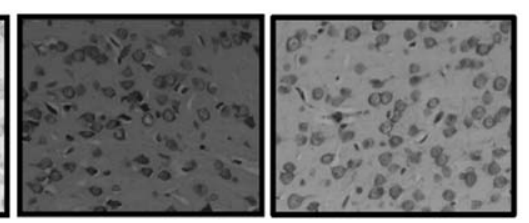

Hp Hp + 7-ACAG (1 h)

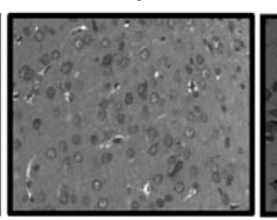

$\mathrm{Hp}+$ $\alpha$-Tocopherol

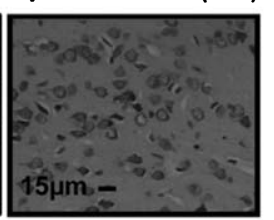

$H p+V e h$

Fig. 7. 7-ACAG decreases neural damage in rat brain cortex and hippocampus caused by hemiplegia. Quantitative analysis in neuronal density caused by Hemiplegia (Hp) induction is shown in the ipsilateral hippocampus and brain cortex (Panels A and C). Slices of hippocampus and brain cortex stained by means of the Nissl method are shown in Panels B and D, respectively. Brain cortex damage reduces neuronal density in the hippocampal CA1 area. 7-ACAG treatments applied either $1 \mathrm{~h}$ or 1 day after Hp reduces neural loss. Similar effects are produced by administration of $\alpha$-Tocopherol. The vehicle did not produce this effect. Scale bars: $15 \mu \mathrm{m}$.

convulsions induced by BIC, a competitive antagonist of $\mathrm{GABA}_{\mathrm{A}}$ receptors. 7-ACAG also increased the threshold of BIC-induced myoclonic seizures and delayed progression to tonic convulsion. Furthermore, at doses of 20 and $40 \mathrm{mg} / \mathrm{kg}, 7-\mathrm{ACAG}$ reduced the incidence of death by up to $72 \%$, while DZ only reduced this up to $50 \%$. Moreover, in brain slices, 7-ACAG exerted an inhibitory effect on the synaptic response in the hippocampal CA1 area. It increased GABAergic activity and decreased the hyperexcitability effect induced by BIC. Increased doses of 7-ACAG had a similar response both in vitro and in vivo; thus, data suggest the participation of GABAergic activity in these responses. In vivo, the behavioral and possible anticonvulsant effects of 7-ACAG are similar to those of DZ, while in vitro, changes induced in the PP protocol, that is, reduction of fEPSP slope and blockade of BIC effects, resemble $\mathrm{GABA}_{\mathrm{A}}$ receptor modulation.

Data obtained from 7-ACAG treatment in Hp rats suggest that this compound exerts a protective effect, because it does not induce changes on in vivo basal synaptic activity (EEG). However, it contributes to increasing contralateral hemisphere activity during the recovery process. Moreover, histological analysis of brains from $\mathrm{Hp}$ rats treated with 7-ACAG showed that neuronal density did not decrease, even under Hp conditions. Therefore, taken together, electrophysiological and histological results support that 7-ACAG protects brain tissue against damage caused by $\mathrm{Hp}$ and suggest that it also acts as a neuroplasticity inducer. 
Previously, it was shown that some flavonoid glycosides, such as rutin, neohesperidin, and linarin, possess sedative effects in rodents (Raines et al., 2009; Fernández et al., 2006). In this paper, we found that 7-ACAG decreases exploratory behavior and locomotion activity in mice in a dose-response manner, indicating its sedative effects. In addition, 7-ACAG exerted sedative effects similar to those induced by DZ at $1-2 \mathrm{mg} / \mathrm{kg}$. Thus, and because DZ acts on GABA receptors, the activity of 7-ACAG can be related with positive modulation of GABAergic neurotransmission. In this regard, it has been described that some flavone glycosides, such as hesperidin, show direct activity on the $\mathrm{GABA}_{\mathrm{A}}$ receptors expressed in oocytes, which possess pentameric structures made up of $\alpha 1 \beta 2 \gamma 2$ subunits. In addition, some aglycone flavonoids, such as chrysin, can potentiate $\mathrm{Cl}^{-}$currents by $490 \%$ (Yang et al., 2011; Rueda et al., 2014) and induce powerful hyperpolarizations in cultured neurons (Jin et al., 2013; Jones et al., 2009; Cho et al., 2011). Therefore, the interaction of 7-ACAG and the GABA receptor is plausible. Thus, we suggest that 7-ACAG modulates the $\mathrm{GABA}_{\mathrm{A}}$ receptor and potentiates $\mathrm{Cl}^{-}$entry into cells (Lopes et al., 2004). In support of this notion in vitro, we identified that 7-ACAG is capable of decreasing the hyperexcitability effect produced by BIC and increasing the PPi, similarly to GABA. It is also known that dihydroxyflavone binds to the BDZ binding site in the $\mathrm{GABA}_{\mathrm{A}}$ receptor (Wang et al., 2002). This evidence, together with the results obtained in this study, suggests that the antiepileptic effects of 7-ACAG in mice could be caused by the interaction of this compound with the $\mathrm{GABA}_{\mathrm{A}}$ receptor.

In this work, we showed that 7-ACAG caused a reversible decrease in hippocampal CA1 synaptic activity, and decreased epileptiform activity in the presence of BIC was observed with 7-ACAG. Together, these data strongly suggest that 7-ACAG directly stimulates the GABAergic receptor (Calixto et al., 2003). Moreover, PP stimulation supports that this effect is modulated by GABAergic interneurons activation and discards the participation of glutamatergic activity or low voltage-dependent $\mathrm{Cl}^{-}$channels (Calixto et al., 2000). Furthermore, 7-ACAG can comprise a selective postsynaptic modulator of GABAergic neurotransmission because of its reversible dose-dependent effect: the increase in PPi and the decrease of the hyperexcitability effect induced by BIC. Data suggest that GABA modulates its ionotropic receptor for long periods of time, similarly to BDZ.
In this paper, we studied 7-ACAG effects on the hippocampus, because $\mathrm{GABA}_{\mathrm{A}}$ receptor activity is involved in the processes of learning and memory. Also, in vitro studies show that bioactive molecules with a similar structure to flavonoids can be either partial or direct agonists of the $\mathrm{GABA}_{\mathrm{A}}$ receptor (Wang et al., 2007). Thus, taken together, these data support that 7-ACAG binds to $\mathrm{GABA}_{\mathrm{A}}$ receptor and that this interaction may displace the binding of BIC from the GABA site. This would grant an inhibitory and anticonvulsant effect to 7-ACAG (Fig. 8).

In this study, we demonstrated that $\alpha$-Tocopherol induces similar effects to those of 7-ACAG; therefore, we are unable to discard that Free radical (FR) scavenger activity, in addition to GABA modulation, may account for 7-ACAG protective effects. Application of $\alpha$-Tocopherol, an FR scavenger and antioxidant (Osakada et al., 2003), induced Hp recovery similar to 7-ACAG. Some flavonoids are capable of scavenging FR of oxygen generated by inflammatory processes and injuries responsible for tissular damage (Chen et al., 1990; Dong et al., 2013). Therefore, it is possible that 7-ACAG induces functional recovery of Hp rats by capturing Reactive oxygen species (ROS) treated with 7-ACAG because they significantly recovered their motor activity and neuronal loss caused by $\mathrm{Hp}$ in the CA1 hippocampal region and somatomotor cortex. These results are similar to those obtained by the application of $\alpha$-Tocopherol. Thus, in our findings, we identified that both compounds (7-ACAG and $\alpha$-Tocopherol) produced protection for neuronal networks of brain cortex (Lebeau et al., 2001; Meng et al., 2014). In this regard, 7-ACAG reduced brain cortex damage by $80 \%$, while reduction of damage in the hippocampus CA1 area was about $60 \%$. These variations can originate from the difference in neuronal communication between these two areas and by the difference in their glial cell density. According to this, some flavonoids protect cells from traumatic brain damage (Leonardo et al., 2013). Thus, all of these data suggest that 7-ACAG induces positive neuronal plasticity by decreasing oxygen-dependent FR.

Together, this evidence indicates that 7-ACAG is a flavone glucoside that belongs to the neuroactive family of flavonoids with therapeutic, possible anticonvulsant, anxiolytic, and hypnotic effects (Wang et al., 2005; Tsang \& Xue, 2004).

After an important brain damage, functional recovery depends on the activity of contralateral hemispheres (Axelson et al., 2013). In this study, we showed 

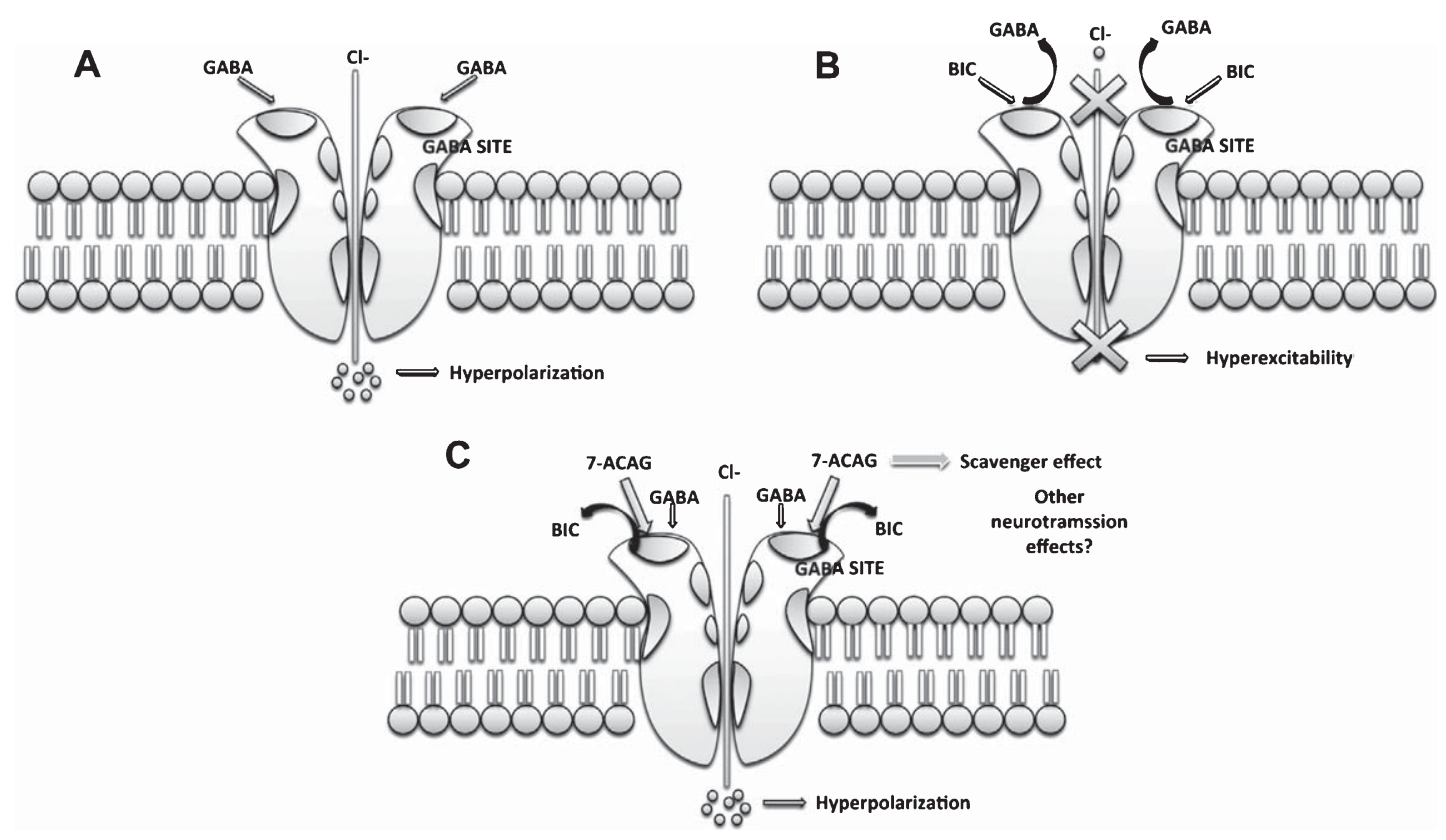

Fig. 8. Possible mechanisms of action of 7-ACAG. A) GABA increases $\mathrm{Cl}^{-}$entry, hyperpolarizing the cell membrane. B) Bicuculline (BIC) blocks the GABA binding site, inducing hyperexcitability. C) 7-ACAG displaces BIC from the GABA binding site reversing the blockade effect induced by BIC. Moreover, it is possible that 7-ACAG can be involved in the modulation of other neurotransmissions and produce other effects.

that EEG activity is increased in the contralateral hemisphere $48 \mathrm{~h}$ after $\mathrm{Hp}$ injury as previously described (Goldstein \& Bullman, 1999) and in functional recovery after ischemic stroke in humans (Kim et al., 2014). Therefore, the data presented here establish the importance of the left hemisphere and its communication with the injured side. Furthermore, systemic application of 7-ACAG either $1 \mathrm{~h}$ or $24 \mathrm{~h}$ after induction of $\mathrm{Hp}$ significantly increases the activity of the contralateral brain hemisphere, supporting this concept. Also, the mechanisms by which the contralateral hemisphere is overactivated are related with a decrease of GABA receptor availability (Kim et al., 2014). Thus, evidence allows suggesting that the effect of 7-ACAG on functional recovery can be related with initial phases with GABAergic modulation and in maintenance phases with antioxidant, anti-inflammatory or FR scavenger effects. However, it is important to consider that some works related with stroke show that effect of the contralateral hemisphere appears to ameliorate recovery (Assenza et al., 2013; Sun et al., 2012). Future works must be focused on comparing the role of the hemispheres on ischemia and stroke models.

Our results indicate that injuries caused by aspiration of the right somatomotor cortex have negative repercussions on the motor behavior of old rats, as previously shown (Brailowsky et al., 1995; Zepeda et al., 1999) In this study, we also found that young rats recover faster (in 1 week). Brain damage induced in one of the hemispheres can generate a selective increase in the electrical activity of the contralateral anatomic structures during the recovery process. This has been especially reported in brain injury in striatum, substantia nigra, and contralateral thalamus and is related with changes in GABAergic activity (Jones \& Schallert, 1992). Also, the contralateral hemisphere of a brain injury presents an increment in dendritic arborization of pyramidal cells from layer V (Jones \& Schallert, 1994), which can be related with the increase in the lefthemisphere's electric signal. In this respect, we showed in our study an increased power by Wavelet analysis. In addition, hesperidin, a well-characterized flavonoid (Oztanir et al., 2014), increased both Brain-derived neurotrophic factor (BDNF) expression and the recovery process during traumatic damage (Spencer et al., 2009). Therefore, data suggest that 7-ACAG may increase BDNF synthesis and release. Finally, the role of the contralateral hemisphere in functional recovery has been partially studied. Brain hemispheres were separated by performing a callosotomy 20 days after 
induction of brain damage, and no interference with the maintenance mechanisms of the chronic recovery was appreciated (Zepeda et al., 1999). In contrast, our data showed the importance of the contralateral hemisphere in functional recovery. Our analysis indicates that the activation process of contralateralhemisphere brain damage occurs immediately within a critical window of $48 \mathrm{~h}$ and is enhanced by 7 ACAG.

\section{Conclusions}

Results obtained from behavioral tests, histological analyses, and in vivo and in vitro recordings support that 7-ACAG can modulate GABAergic activity and confer neuroprotection that contributes to functional recovery after brain damage. The future development and use of flavonoids with sedative and neuroprotective effects should be explored. Finally, the results suggest the use of 7-ACAG as an alternative pharmacological treatment for traumatic brain damage, strokes, and for post-operative conditions caused by neurosurgeries or diseases such as Alzheimer disease.

\section{Acknowledgments}

The authors would like to thank Rubén LuvianoJaramillo for assisting in animal care. In addition, we would like to thank Sonia Santos and the staff of the Departamento de Diseño Gráfico, Audiovisual y Difusión Académica de la Dirección de Enseñanza of the Instituto Nacional de Psiquiatría Ramón de la Fuente Muñiz for technical services provided. Partial support came from Project No. 190 of Fondo de Apoyo para Proyectos de Investigación 2009 del Instituto Nacional de Psiquiatría Ramón de la Fuente Muñiz and CONACYT (Ph.D. of the Ciencias Biomédicas Program 2007) and CONACyT SEP Grant No. 1666823.

\section{References}

Assenza, G., Zappasodi, F., Pasqualetti, P., Vernieri, F., \& Tecchio, F. (2013). A contralesional EEG power increase mediated by interhemispheric disconnection provides negative prognosis in acute stroke. Restor Neurol Neurosci, 31(2), 177-188.

Archer, J. (1973). Tests for emotionality in rats and mice: A review. Anim Behav, 21, 205-235.
Axelson, H.W., Winkler, T., Flygt, J., Djupsjo, A., Hanell, A., \& Marklund, N. (2013). Plasticity of the contralateral motor cortex following focal traumatic brain injury in the rat. Restor Neurol Neurosci, 31(1), 73-85.

Brailowsky, S., Montiel, T., \& Medina-Ceja, L. (1995). Acceleration of functional recovery from motor cortex ablation by two Ginkgo biloba extracts in rats. Restor Neurol Neurosci, 8(4), 163-167.

Bye, R., \& Linares, E. (1983). The role of plants found in the Mexican markets and their importance in ethnobotanical studies. J Ethnobiol, 3(1), 1-13.

Bye, R., Linares, E., Ramamoorthy, T.P., García, F., Collera, O., Palomino, G., \& Corona, V. (1987). Agastache mexicana subsp. xolocotziana (Lamiaceae). A new taxon from the Mexican medicinal plants. Phytologia, 3,156-163.

Calixto, E., López-Colomé, A.M., Casasola, C., Montiel, T., Bargas, J., \& Brailowsky, S. (2000). Neocortical hyperexcitability after GABA withdrawal in vitro. Epilepsy Res, 39(1), 13-26.

Calixto, E., Thiels, E., Klann, E., \& Barrionuevo, G. (2003). Early maintenance of hippocampal mossy fiber long-term potentiation depends on protein and RNA synthesis and presynaptic granule cell integrity. $J$ Neurosci, 23(12), 4842-4849.

Cassani, J., Araujo, A.G., Martínez-Vázquez, M., Manjarréz, N., Moreno, J., \& Estrada-Reyes, R. (2013). Anxiolytic-like and antinociceptive effects of 2(S)-neoponcirin in mice. Molecules, $18,7584-7599$.

Chen, Y.T., Zheng, R.L., Jia, Z.J., \& Ju, Y. (1990). Flavonoids as superoxide scavengers and antioxidants. Free Radic Biol Med, 9(1), 19-21.

Cho, S., Kim, S., Jin, Z., Yang, H., Han, D., Baek, N.I., Jo, J., Cho, C.W., Park, J. H., Shimizu, M., \& Jin, Y.H. (2011). Isoliquiritigenin, a chalcone compound, is a positive allosteric modulator of $\mathrm{GABA}_{\mathrm{A}}$ receptors and shows hypnotic effects. Biochem Biophys Res Commun, 413(4), 637-642.

Dong, S., Tong, X., Li, J., Huang, C., Hu, C., Jiao, H., \& Gu, Y. (2013). Total flavonoid of Litsea coreana H.Lev. exerts antioxidative effects and alleviates focal cerebral ischemia/ reperfusion injury. Neural Regen Res, 8(34), 3193-3202.

Estrada-Reyes, R., Aguirre-Hernández, E., García-Argáez, A., Soto-Hernández, M., Linares, E., Bye, R., Heinze, G., \& Martínez-Vázquez, M. (2004). Comparative chemical composition of Agastache mexicana subsp. mexicana and A. mexicana subsp. xolocotziana. Biochem System Ecol, 32, 685-694.

Estrada-Reyes, R., Martínez-Vázquez, M., Gallegos-Solís, A., Heinze, G., \& Moreno, J. (2010). Depressant effects of Clinopodium mexicanum Benth. Govaerts (Lamiaceae) on the central nervous system. J Ethnopharmacol, 130, 1-8.

Estrada-Reyes, R., López-Rubalcava, C., Ferreira-Cruz, O., Dorantes-Barrón, A., Heinze, G., Moreno, J., \& MartínezVázquez, M. (2014). Central nervous system effects and chemical composition of two subspecies of Agastache mexicana; and ethnomedicine of Mexico. J Ethnopharmacol, 153, 98-110.

Fernández, S.P., Wasowski, C., Loscardo, L.M., Granger, R.E., Johnston, G.A.R., Paladini, A.C., \& Marder, M. (2006). Central nervous system depressant action of flavonoid glycosides. Eur J Pharmacol, 539,168-176. 
Goldstein, L.B., \& Bullman, S. (1999). Age but not sex affects motor recovery after unilateral sensorimotor cortex suction-ablation in the rat. Restor Neurol Neurosci, 15(1), 39-43.

Guide for the Care and Use of Laboratory Animals. NIH Publication No. 85-23. Revised 1985.

Hernández-Abreu O., Castillo-España P., León-Rivera I., IbarraBarajas M., Villalobos-Molina R., González-Christen J., Vergara-Galicia J., \& Estrada-Soto S. (2009). Antihypertensive and vasorelaxant effects of tilianin isolated from Agastache mexicana are mediated by NO/cGMP pathway and potassium channel opening. Biochem Pharmacol, 78(1), 54-61.

Jin, Z., Kim, S., Cho, S., Kim, I.H., Han, D., \& Jin, Y. H. (2013). Potentiating effect of glabridin on $\mathrm{GABA}_{\mathrm{A}}$ receptor-mediated responses in dorsal raphe neurons. Planta Med, 79(15), 1408-1412.

Jones, P., Moe, N., Duncan, R., McCall, S., \& Ceremuga, T.E. (2009). Investigation of the anxiolytic effects of luteolin, a lemon balm flavonoid in the male Sprague-Dawley rat. Raines T1. AANA Journal of the American Association of Nurse Anesthetists, 77(1), 33-36.

Jones, T.A., \& Schallert, T. (1992). Subcortical deterioration after cortical damage: Effects of Diazepam and relation to recovery of function. Behav Brain Res, 51(1), 1-13.

Jones, T.A., \& Schallert, T. (1994). Use-dependent growth of pyramidal neurons after neocortical damage. J Neurosci, 14(4), 2140-2152.

Kim Y.K., Yang, E.J., Cho K., Lim J., \& Paik N.J. (2014). Functional recovery after ischemic stroke is associated with reduced GABAergic inhibition in the cerebral cortex: A GABA PET study. NNR Neurorehabilitation \& Neural Repair 28(6), 576-583.

Lebeau, A., Esclaire, F., Rostène, W., \& Pélaprat, D. (2001). Baicalein protects cortical neurons from $\beta$-amyloid (25-35) induced toxicity. Neuroreport, 12(10), 2199-2202.

Leonardo, C.C., Agrawal, M., Singh, N., Moore, J. R., Biswal, S., \& Doré, S. (2013). Oral administration of the flavanol (-)-epicatechin bolsters endogenous protection against focal ischemia through the Nrf2 cytoprotective pathway. Eur J Neurosci, 38(11), 3659-3668.

Liu, X., Yue, R., Zhang, J., Shan, L., Wang, R., \& Zhang, W. (2013). Neuroprotective effects of bacopaside I in ischemic brain injury. Restor Neurol Neurosci, 31, 109-123.

Lopes, D.V., Caruso, R.R., Castro, N.G., Costa, P. R., da Silva, A.J., \& Noël, F. (2004). Characterization of a new synthetic isoflavonoid with inverse agonist activity at the central benzodiazepine receptor. Eur J Pharmacol, 495(2-3), 87-96.

López-Rubalcava, C., Piña-Medina, B., Estrada-Reyes, R., Heinze, G., \& Martínez-Vázquez, M. (2006). Anxiolytic-like actions of the hexane extract from leaves of Annona cherimolia in two anxiety paradigms: Possible involvement of the GABA/benzodiazepine receptor complex. Life Sci, 78, 730-737.

Martínez-Vázquez, M., Estrada-Reyes, R., Martínez-Laurrabaquio, M., López-Rubalcava C., \& Heinze, G. (2012). Neuropharmacological study of Dracocephalum moldavica L. (Lamiaceae) in mice: Sedative effect and chemical analysis of an aqueous extract. J Ethnopharmacol, 141, 908-917.
Meng, J., Li, Y., Camarillo, C., Yao, Y., Zhang, Y., Xu, C., \& Jiang, L. (2014). The anti-tumor histone deacetylase inhibitor SAHA and the natural flavonoid curcumin exhibit synergistic neuroprotection against amyloid-beta toxicity. (Abstract). PLOS ONE, 9(1), e85570.

Nam, Kung-woo, Kim., Jiyun, Hong., Jung-Joo, Choi., Jae-Hoon, Mar., Woonchon, Cho., Myung-Haing., Young-Myeong., Oh, Sei-Ryang, Lee., Hyeong-kyu, Ki-Hoan., \& Goo Taeg. (2005). Inhibition of cytokine-induced IкB kinase activation as a mechanism contributing to the anti-atherogenic activity of tilianin in hyperlipidemic mice. Atherosclerosis 180(1), 27-35.

Okuyama, S., Morita, M., Miyoshi, K., Nishigawa, Y., Kaji, M., Sawamoto, A., Terugo, T., Toyoda, N., Makihata, N., Amakura, Y., Yoshimura, M., Nakajima, M., \& Furukawa, Y. (2014). 3,5,6,7,8,3',4'-Heptamethoxyflavone, a citrus flavonoid, on protection against memory impairment and neuronal cell death in a global cerebral ischemia mouse model. Neurochem Int, 70 , 30-38.

Osakada, F., Hashino, A., Kume, T., Katsuki, H., Kaneko, S., \& Akaike, A. (2003). Neuroprotective effects of alpha-Tocopherol on oxidative stress in rat striatal cultures. Eur J Pharmacol, 465(1-2), 15-22.

Oztanir, M., Ciftci, O., Cetin, A., \& Aladag M. (2014). Hesperidin attenuates oxidative and neuronal damage caused by global cerebral ischemia/reperfusion in a C57BL/J6 mouse model. Neurol Sci, 35, 1393-1399.

Paxinos, G., \& Watson, C. (1998). The Rat Brain in Stereotaxic Coordinates. New York: Academic Press.

Raines, T., Jones, P., Moe, N., Duncan, R., McCall, S., \& Ceremuga, T.E. (2009). Investigation of the anxiolytic effects of luteolin, a lemon balm flavonoid in the male Sprague-Dawley rat. AANA Journal of the American Association of Nurse Anesthetists, 77(1), 33-36.

Rueda, D.C., De Mieri, M., Hering, S., \& Hamburger, M. (2014). HPLC-based activity profiling for $\mathrm{GABA}_{\mathrm{A}}$ receptor modulators in Adenocarpus cincinnatus. J Nat Prod, 77(3), 640-649.

Shen-Yun, W., Hui-Hung, W., Chin-Wen, C., Chieh-Fu, C., \& Jyh-Fei, L. (2004) Effects of baicalein on $\beta$-amyloid peptide(25-35)-induced amnesia in mice. Eur JPharmacol, 506(1), $55-61$.

Spencer, J.P., Vauzour, D., \& Rendeiro, C. (2009). Flavonoids and cognition: The molecular mechanisms underlying their behavioral effects. Arch Biochem Biophys, 492(1-2), 1-9.

Sun, F., Xiel, L., Mao, X., Hill, J., Greenberg, D.A., \& Jin K. (2012). Effect of a contralateral lesion on neurological recovery from stroke in rats. Restor Neurol Neurosci, 30(6), 491-495.

Tsang, S.Y., \& Xue, H. (2004). Development of effective therapeutics targeting the GABAA receptor: Naturally occurring alternatives. Curr Pharm Des, 10(9), 1035-1044.

Walsh, R.N., \& Cummins, R.A. (1976). The Open-field test: A critical review. Psychol Bull, 83(3), 482-504.

Wang, F., Shing, M., Huen, Y., Tsang, S.Y., \& Xue, H. (2005). Neuroactive flavonoids interacting with GABAA receptor complex. Curr Drug Targets CNS Neurol Disord, 4(5), 575-585.

Wang, F., Xu, Z., Yuen, C. T., Chow, C.Y., Lui, Y. L., Tsang, S.Y., \& Xue, H. (2007). Dihydroxyflavone, a subtype-selective 
partial inverse agonist of $\mathrm{GABA}_{\mathrm{A}}$ receptor benzodiazepine site, Neuropharmacology, 53(4), 574-582.

Wang, C.G., Mehendale, S.R., Calway, T., \& Yuan, C.S. (2011). Botanical flavonoids on coronary heart disease. Am J Chin Med, 39(4), 661-671.

Wang, H., Hui, K.M., Xu, S., Chen, Y., Wong, J.T., \& Xue, H. (2002). Two flavones from Scutellaria baicalensis Georgi and their binding affinities to the benzodiazepine site of the $\mathrm{GABA}_{\mathrm{A}}$ receptor complex. Pharmazie, 57(12), 857-858.

West, M.J. (1993). New tereological methods for counting neurons. Neurobiol Aging, 14, 275-285.

Yang, X., Baburin, I., Plitzko, I., Hering, S., \& Hamburger, M. (2011). HPLC-based activity profiling for GABAA receptor modulators from the traditional Chinese herbal drug Kushen (Sophora flavescens root). Mol Divers, 2, 361-372.
Yu, C., Zhang, Z., Zhang, H., Zhen, Z., Calway, T., Wang, Y., \& Wang, C. (2013). Pretreatment of baicalein and wogonoside with glycoside hydrolase: A promising approach to enhance anticancer potential. Oncol Rep, 30, 2411-2418.

Zepeda, A., Montiel, T., \& Brailowsky, S. (1999). Functional recovery from cortical hemiplegia in the rat: Effects of a callosotomy. J Neurotrauma, 16(3), 267-271.

Zhang, S.Q., Obregón, D., Ehrhart, J., Deng, J., Tian, J., Hou, H., Giunta, B., Sawmiller, D., \& Tan, J. (2013). Baicalein reduces $\beta$-amyloid and promotes nonamyloidogenic amyloid precursor protein processing in an Alzheimer's disease transgenic mouse model. J Neurosci Res, 91(9), 1239-1246. 